\title{
Article \\ Chemical Profiling of Pistacia lentiscus var. Chia Resin and Essential Oil: Ageing Markers and Antimicrobial Activity
}

\author{
Vasiliki K. Pachi ${ }^{1}{ }^{\oplus}$, Eleni V. Mikropoulou ${ }^{1}{ }^{\circledR}$, Sofia Dimou ${ }^{2}$, Mariangela Dionysopoulou ${ }^{2}{ }^{\circledR}$, \\ Aikaterini Argyropoulou ${ }^{3}$, George Diallinas ${ }^{2,4}$ and Maria Halabalaki ${ }^{1, *}$ (D) \\ 1 Division of Pharmacognosy and Natural Products Chemistry, Department of Pharmacy, National and \\ Kapodistrian University of Athens, Panepistimiopolis Zografou, 15771 Athens, Greece; \\ vpachi@pharm.uoa.gr (V.K.P.); elenamik@pharm.uoa.gr (E.V.M.) \\ 2 Department of Biology, National and Kapodistrian University of Athens, Panepistimiopolis Zografou, \\ 15784 Athens, Greece; sofiadimou123@gmail.com (S.D.); mariangeladiony@gmail.com (M.D.); \\ diallina@biol.uoa.gr (G.D.) \\ 3 PharmaGnose S.A., 57th km Athens-Lamia National Road, 32011 Oinofyta, Greece; \\ kargyropoulou@pharmagnose.com \\ 4 Institute of Molecular Biology and Biotechnology, Foundation for Research and Technology, \\ 70013 Heraklion, Greece \\ * Correspondence: mariahal@pharm.uoa.gr; Tel.: +30-2107-2747-81
}

Citation: Pachi, V.K.; Mikropoulou, E.V.; Dimou, S.; Dionysopoulou, M.; Argyropoulou, A.; Diallinas, G.; Halabalaki, M. Chemical Profiling of Pistacia lentiscus var. Chia Resin and Essential Oil: Ageing Markers and Antimicrobial Activity. Processes 2021, 9, 418. https://doi.org/ $10.3390 /$ pr9030418

Academic Editors: Adriana Trifan,

Elwira Sieniawska and

Greige-Gerges Helene

Received: 29 January 2021

Accepted: 21 February 2021

Published: 25 February 2021

Publisher's Note: MDPI stays neutral with regard to jurisdictional claims in published maps and institutional affiliations.

Copyright: (c) 2021 by the authors. Licensee MDPI, Basel, Switzerland. This article is an open access article distributed under the terms and conditions of the Creative Commons Attribution (CC BY) license (https:/ / creativecommons.org/licenses/by/ $4.0 /)$.

\begin{abstract}
Chios Mastic Gum (CMG) and Chios Mastic Oil (CMO) are two unique products of the tree Pistacia lentiscus var. Chia, cultivated exclusively on the Greek island of Chios. In the present study, the method proposed by the European Pharmacopoeia for mastic identification was employed using HPTLC together with an in-house method. A GC-MS methodology was also developed for the chemical characterization of CMOs. $\alpha$-Pinene and $\beta$-myrcene were found in abundance in the fresh oils; however, in the oil of the aged collection, oxygenated monoterpenes and benzenoids such as verbenone, pinocarveol, and $\alpha$-campholenal were found at the highest rates. Additionally, the antimicrobial activity of Chios Mastic Gums (CMGs) with their respective Chios Mastic Oils (CMOs) was evaluated, with growth tests against the fungi Aspergillus nidulans, Aspergillus fumigatus, Candida albicans, Mucor circinelloides, and Rhizopus oryzae, and the bacteria Escherichia coli, Pseudomonas aeruginosa and Bacillus subtilis, with the samples exhibiting a moderate activity. To our knowledge, this is the first time that an HPTLC method is proposed for the analysis of mastic and its essential oil and that a standardized methodology is followed for the distillation of CMO with a parallel assessment of the ageing effect on the oil's composition.
\end{abstract}

Keywords: Pistacia lentiscus var. Chia; Chios mastic; ageing; chemical profile; antibacterial; antifungal; $\alpha$-pinene; $\beta$-myrcene; GC-MS; HPTLC

\section{Introduction}

Pistacia lentiscus var. chia (Anacardiaceae) is an evergreen shrub cultivated exclusively in the southern part of the Greek island of Chios [1]. The most characteristic products are the resin or Chios Mastic Gum (CMG), produced from the wounds of the bark and branches, and the essential oil, Chios Mastic oil (CMO), which is obtained by hydrodistillation from the resin. Even though the Pistacia species are widely distributed in the Mediterranean basin and in circum-Mediterranean areas, CMG is a unique resin of the mastic trees grown only in the southern part of the island of Chios. Attempts to cultivate it in different areas, even at the north part of the island, were not successful, failing to produce resin with specific physicochemical and organoleptic characteristics. In that view, CMG and CMO are both Protected Designation of Origin (PDO) products [2] while the know-how of cultivating mastic on the island of Chios was included by UNESCO in the Representative List of the Intangible Cultural Heritage of Humanity [3]. In 2015, Pistacia lentiscus L. resin (mastix or mastic), was recognized by the European Medicines Agency (EMA) as a traditional herbal 
medicinal product with two indications, i.e., for the treatment of mild dyspeptic disorders, skin inflammations, and as an aid in the healing of minor wounds [4].

For over 2500 years, the resin has been used in the ethnopharmacology of the Mediterranean populations. In the 1st century AD, Dioscorides, reported in his work "De Materia Medica" that CMG and CMO were effective against minor gastrointestinal disorders and proposed their use for the skin's and the oral cavity's care [5]. In the 2nd century AD, Galen also reported the beneficial effects of CMG against stomachache and dysentery [6]. Later on, several references can be found containing mastic as an ingredient of multiple medicinal preparations, with probably the most noteworthy being the "Jerusalem balsam", which was served as a "panacea" and was included in numerous European Pharmacopoeias until the 20th century [7].

In contemporary times, $\mathrm{CMG}$ and $\mathrm{CMO}$ have been studied for their composition as well as their biological and pharmacological properties. However, the number of available studies remains relatively small. CMG and CMO have been reported as potent antioxidant [8,9], anti-inflammatory [10,11], cardioprotective [12-14], and chemopreventive agents [15-19]. Over the recent years, the increasing number of clinical or intervention trials examining the effect of mastic administration on different disease models further validates the Mediterranean populations' inherent knowledge regarding mastic's therapeutic potential. Interestingly, CMG's anti-inflammatory activity has been demonstrated in pilot studies involving patients with active Crohn's disease and inflammatory bowel syndrome (IBS) $[10,20]$, and CMG has been suggested as a possible cardioprotective and hepatoprotective agent in a pilot study describing a long term mastic administration in a human cohort [21]. Moreover, in a prospective, randomized, placebo-controlled clinical study, daily mastic consumption by healthy volunteers led to a significant decrease of their total cholesterol and glucose levels [22], while in a recently published research, mastic administration led to the regulation on peripheral and aortic blood pressure hemodynamics in hypertensive patients [23].

It is worth mentioning that one of the first pharmacological properties of $\mathrm{CMG}$ and $\mathrm{CMO}$ that were examined by modern day science was their antimicrobial activity, and especially their efficacy against Helicobacter pylori and oral and periodontal pathogens [24-30]. In fact, according to the study of Miyamoto et al., CMO exhibits a notable anti-H. pylori activity against four different strains, established from patients with gastritis, gastric ulcer, and gastric cancer [26]. In addition, $\mathrm{CMO}$ was found potent against several food-borne microorganisms such as Staphylococcus aureus, Escherichia coli, and Salmonella sp. [24,25,27,29,31]. Furthermore, both CMG and CMO are used in numerous products and have a wide spectrum of applications. $\mathrm{CMO}$ is used due to its distinguishing aroma in alcoholic drinks [32] and as a perfume and a perfume stabilizer [33] as well as in cosmetic products for the mouth and skin care [34]. CMG is incorporated in many traditional bakery products, confections, and desserts $[32,35]$. Moreover, the resin is widely found in food supplements and phytotherapeutic products due to its long-term documented ethnobotanical medicinal use as well as recent studies [34].

From a chemical point of view, CMG constitutes an entity of more than 120 compounds reported thus far, primarily terpenes. Triterpenes, mainly tetracyclic and pentacyclic, constitute the major chemical group of $\mathrm{CMG}$, comprising approximately $65-70 \%$ of the total resin weight. Its composition is complemented by the fraction of volatile components which constitute the essential oil of mastic (CMO) [1]. All these compounds coexist with the natural polymer, poly- $\beta$-myrcene (25-30\% of the dry weight), forming the resin structure. $\mathrm{CMO}$ is typically produced by steam and/or water distillation [36], while Supercritical Fluid Extraction (SFE) has been recently developed as an alternative method to the existing ones [37]. CMO constitutes approximately $3 \%$ of the resin weight when harvested by the traditional way and about $13 \%$ when harvested in a fluid form [38]. The chemical composition of the essential oil has been studied mainly by the GC-MS and GC-FID techniques [38-40].

CMG is often extensively adulterated because of the resin's uniqueness and high commercial value [41]. Adulteration is mainly achieved by mixing mastic with similar 
resins of lower economic value such as Iranian mastic (Pistacia atlantica), Boswellia resin (frankincense), or Pinus resin, together with packing falsification [42]. However, special attention should be paid to the fact that the Pistacia lentiscus var. Chia tree, as well as its resin, can be found in the literature with various different names such as "schinos" or "lentisk" without the authors specifying the geographical origin or variety. Additionally, very often, the source of the resin and/or the essential oil under investigation is vague or not defined, a fact which further complicates the identification of Pistacia lentiscus originating from Chios island (var Chia), which is distinguished for its unique aroma characteristics [43]. CMG is often found in the market as simply mastic or mastic gum, Chios masticha, mastiha, mastihi, and mastix. Moreover, another misperception is often encountered regarding mastic oil or "mastichelaion" (as described by Dioscorides), which is the essential oil of the resin and is often confused with Pistacia lentiscus oil or "schinelaion", the essential oil obtained possibly from the plant's berries. Despite the obvious confusion in the literature regarding both the provenance of the resin and its essential oil but also the terminology employed, CMO is used to this day to define and differentiate CMG from other resins in the respective monograph of the European Pharmacopoeia (Ph. Eur.) [44]. For the identification of the resin according to the Ph. Eur. method, only the analysis of its essential oil is used, including a specific distillation yield (10 mL of essential oil $/ \mathrm{kg}$ of dry resin) and a TLC method for a visual evaluation [44]. Thus far, there is no other suitable and efficient analytical method available for authentication and quality control of CMG and, therefore, adulteration detection [1].

In the present study, different $P$. lentiscus var. Chia resin (CMG) samples together with their produced essential oils (CMO) after hydrodistillation were investigated. Two analytical methods, namely High Performance Thin Layer Chromatography (HPTLC) and GC-MS, were employed for sample profiling, and the Ph. Eur. proposedTLC method was also used for comparison purposes. Special emphasis was given to the exploration of the ageing effect on the CMG and CMO composition, which is a critical parameter of quality and authentication. Finally, both types of samples were evaluated for their antifungal and antibacterial properties against different fungi and bacteria strains, with the Aspergillus nidulans, Aspergillus fumigatus, Mucor circinelloides, and Rhizopus oryzae being tested for the first time. Moreover, to our knowledge, it is the first time that a high number of original CMG and CMO samples are analyzed, and the ageing parameter is investigated so extensively in the essential oil, employing two analytical methods and in comparison to the official monograph of the Ph. Eur.

\section{Materials and Methods}

\subsection{Chemicals and Standards}

Toluene [Ph. Eur., $\geq 99.7 \%$ (GC)] and sulfuric acid (puriss. meets analytical specification of Ph. Eur., BP, 95-97\%) were obtained from Sigma-Aldrich (St. Louis, MO, USA). Dimethyl sulfoxide (for analysis) was purchased from Merck (Kenilworth, NJ, USA). Methanol [ $\geq 99.8 \%$ (HPLC)] and ethanol absolute (99.8\% HPLC grade) were purchased from Fischer Chemical (Pittsburg, PA, USA). Petroleum ether (RPE, for analysis) and ethanol $96^{\circ}$ were provided by Carlo Erba Reagents (Milan, Italy). Dichloromethane (reagent grade) (Scharlau, Barcelona, Spain) was used after distillation for the dilution of the resins and their essential oils for all HPTLC and GCMS analyses. Vanillin used (Acros Organics, Fair Lawn, NJ, USA) was 99\% pure. The alkane C10-C40 analytical standard mixture and the standards borneol (97\% purity) and eugenol (99\% purity) were obtained from Sigma-Aldrich (St. Louis, MO, USA).

\subsection{Starting Material and Production of Essential Oil}

Eleven CMG samples were kindly provided by the Chios Mastiha Growers Association (CMGA). Eight samples (CMG_1-8) were analyzed fresh (2 and 6 months after collection) or slightly aged (2 years), whilst three (CMG_9-11) were aged for a longer time period (over 10 years). The distillation process of the resins was conducted according to the $\mathrm{Ph}$. 
Eur. monograph of Mastic (01/2008:1876), within a period of two weeks for all samples. In brief, $20 \mathrm{~g}$ of resin was reduced to a coarse powder and then distilled for $2 \mathrm{~h}$ in a $500 \mathrm{~mL}$ round-bottomed flask, using $200 \mathrm{~mL}$ of distilled water and a Clevenger apparatus [44]. The produced oils (CMO_1-9) were collected and stored at $4{ }^{\circ} \mathrm{C}$. Two of the aged resins (CMG_10-11) did not produce essential oil and, therefore, were not analyzed further.

\subsection{Profiling of the Resin and Essential Oil by HPTLC}

Eleven resin samples (CMG_1-11) and their respective essential oils (CMO_1-9) were analyzed by HPTLC. Two methods were applied, the 1st according to the Ph. Eur. monograph and the 2nd developed in-house. According to the monograph's instructions, $1 \mathrm{~g}$ of resin was diluted in $10 \mathrm{~mL}$ of dichloromethane, filtered after 1-2 min, and used as the test solution. Moreover, the preparation of a reference solution involving the dilution of $25 \mathrm{mg}$ of eugenol and $25 \mathrm{mg}$ of borneol in $3 \mathrm{~mL}$ of dichloromethane was carried out as indicated in the monograph. For the in-house method, $10 \mathrm{mg}$ of the tested resins were diluted in $1 \mathrm{~mL}$ of dichloromethane with the aid of an ultrasonic bath for 1-2 min. In both methodologies, CMOs were dissolved in dichloromethane at a concentration of $2 \mathrm{mg} / \mathrm{mL}$.

HPTLC analyses were conducted using a CAMAG system $\left(\right.$ CAMAG $^{\circledR}$, Muttenz, Switzerland) consisting of an automatic TLC sampler (ATS4), an automatic development chamber (ADC2), a Visualizer 2 Documentation System, and a Derivatizer, under the control of the software platform VisionCats 2.5 (CAMAG ${ }^{\circledR}$, Muttenz, Switzerland). The samples were applied onto $20 \times 10 \mathrm{~cm}$ HPTLC Silica gel $60 \mathrm{~F}_{254}$ glass plates (Merck, Kenilworth, NJ, USA). Standard and sample solutions were applied band wise with the autosampler ATS4 using a syringe of $25 \mu \mathrm{L}$ (Hamilton, Reno, NV, USA) and a nitrogen aspirator with the following standard settings: Tracks with $8.0 \mathrm{~mm}$ bands, $8 \mathrm{~mm}$ distance from the lower edge, $20 \mathrm{~mm}$ from the left and right edges, and $11.4 \mathrm{~mm}$ between the different tracks, $200 \mathrm{~nL} / \mathrm{s}$ delivery speed. For the Ph. Eur. method, application volume was set to $1 \mu \mathrm{L}$, and the mobile phase consisted of light petroleum of reagent grade $(R)$, toluene $R(5: 95 \mathrm{v} / \mathrm{v})$. For the in-house methodology, the mobile phase consisted of dichloromethane, methanol $(98: 2 v / v)$, and the application volume was set to $10 \mu \mathrm{L}$. In both methodologies, the application volume of the essential oils was $20 \mu \mathrm{L}$. The standard settings used in ADC2 were the following: $20 \mathrm{~min}$ chamber saturation, $10 \mathrm{~min}$ of plate activation (conditioning) at $33 \%$ relative humidity using $\mathrm{MgCl}_{2}$ as a desiccant, and $5 \mathrm{~min}$ of plate drying. The solvent front was set to $8.5 \mathrm{~cm}$. Plate images at $254 \mathrm{~nm}$ and $366 \mathrm{~nm}$ before spraying and at white light after spraying were recorded. For visualization of the spots, the plates were sprayed with vanillin reagent $\mathrm{R}$ [i.e., $2 \mathrm{~mL}$ of sulfuric acid added to $100 \mathrm{~mL}$ of a $10 \mathrm{~g} / \mathrm{L}$ solution of vanillin in ethanol $\left.\left(96^{\circ}\right)\right]$ and heated at $100-105^{\circ} \mathrm{C}$ for $5 \mathrm{~min}$ in the oven. An optical evaluation of the color and shape of the spots was performed according to the monograph's instructions.

\subsection{Determination of Essential Oil Constituents by GC-MS}

All CMO samples were diluted in dichloromethane at a concentration of $2 \mathrm{mg} / \mathrm{mL}$. Analyses were performed on a Finnigan Trace GC Ultra 2000 apparatus (Thermo Electron Corporation, Waltham, MA, USA) with an AI 3000 autosampler. The system was coupled with a Finnigan Trace DSQ mass selective detector at Electron Impact (EI) mode. The separation was achieved on a Trace TR-5MS capillary column $(30 \mathrm{~m} \times 0.25 \mathrm{~mm}$; film thickness $0.25 \mathrm{~m}$ ) (Thermo Scientific, Waltham, MA, USA). Helium ( $1 \mathrm{~mL} / \mathrm{min}$ ) was used as a carrier gas. $1 \mu \mathrm{L}$ of essential oil was directly injected at splitless mode. The initial oven temperature was set to $40{ }^{\circ} \mathrm{C}$, reaching $240^{\circ} \mathrm{C}$ with a gradient of $3{ }^{\circ} \mathrm{C} / \mathrm{min}$. When the temperature reached $240{ }^{\circ} \mathrm{C}$, it was kept steady for $10 \mathrm{~min}$. The injector and source temperatures were set to $220{ }^{\circ} \mathrm{C}$ and $250{ }^{\circ} \mathrm{C}$, respectively. The mass range was set to 40-400 Da and electron energy to $70 \mathrm{eV}$. Spectra acquisition and analysis were performed using the XCalibur 2.2 software platform (Thermo, Waltham, MA, USA). Compound identification was conducted by mass spectra comparison to Willey/NIST 0.5 and in-house libraries [45,46]. For the compounds of C14 and above, the method of retention indices (RI) 
as defined by IUPAC for temperature-programmed GC was additionally used in terms of a better structural verification [47]. A relative quantification of detected compounds was performed by employing the Area \% feature and the auto integration using the ICIS algorithm.

\subsection{Media and Growth Conditions}

Standard minimal media (MM) for A. nidulans was used for the growth of A. nidulans, A. fumigatus, $M$. circinelloides, and $R$. oryzae. Media and supplemented auxotrophies were used at the concentrations given in Fungal Genetics Stock Center (FGSC) [48]. Glucose $1 \%(w / v)$ and $5 \mathrm{mM}$ urea were used as the carbon and nitrogen sources, respectively. Growth tests were performed at $37^{\circ} \mathrm{C}$, at $\mathrm{pH}$ 6.8, and scored after 3-6 days. The C. albicans strain was incubated at $30^{\circ} \mathrm{C}$ in YPD broth pH 6.8 (2\% Bacto peptone, $1 \%$ yeast extract, $2 \%$ dextrose) at $200 \mathrm{rpm}$. Liquid bacterial cultures were incubated in Luria-Bertani (LB) medium pH 6.8 (BactoTryptone $10 \mathrm{~g}, \mathrm{NaCl} 10 \mathrm{~g}$, BactoYeast Extract $5 \mathrm{~g}$ for $1 \mathrm{~L}$ ) at $250 \mathrm{rpm}$. Media and chemical reagents were obtained from Sigma-Aldrich or AppliChem. Mastic resins (CMG_1-8) were diluted in 100\% DMSO or ethanol and added to the media in a final concentration of $0.2 \mathrm{mg} / \mathrm{mL}$ and $0.4 \mathrm{mg} / \mathrm{mL}$, respectively (final 1\% DMSO or $1 \%$ ethanol). Mastic essential oils (CMO_1-8) were diluted in 100\% DMSO and added to the media in a final concentration of $0.2 \mathrm{mg} / \mathrm{mL}(1 \% \mathrm{DMSO})$. Controls were treated with the same concentration of solvent (final 1\% DMSO or ethanol).

\subsection{Epifluorescence Microscopy}

For wide-field epifluorescence microscopy, conidiospores were incubated overnight in glass bottom $35 \mathrm{~mm}$ 1-dishes (ibidi) in liquid minimal media, for 16-22 h at $25{ }^{\circ} \mathrm{C}$, supplemented with glucose $1 \%(w / v)$ and urea at $5 \mathrm{mM}$. Mastic resins (CMG_1-8) were diluted in ethanol and added to the media in a final concentration of $0.4 \mathrm{mg} / \mathrm{mL}(1 \%$ ethanol). Images were obtained using an inverted Zeiss Axio Observer Z1 (Zeiss, White Plains, NY, USA) equipped with a Hamamatsu ORCA Flash 4.0 CMOS camera using the Zen lite 2012 software (Hamamatsu Photonics Deutschland GmbH, Herrsching am Ammersee, Germany). Images were processed and annotated in Adobe Photoshop CS4 Extended version 11.0.2 (Adobe, San Jose, CA, USA).

\section{Results and Discussion}

\subsection{Hydrodistillation Yield}

The yield of hydrodistillation plays a key role in CMG identification, since according to the Ph. Eur. monograph for mastic, a minimum of $10 \mathrm{~mL}$ of essential oil $/ \mathrm{kg}$ of anhydrous resin is required as a quality marker [44]. In the current study, only the fresh and slightly aged samples (CMG_1-8) produced essential oil, whilst the three aged samples (CMG_9-11) produced $C M O$ either in traces $\left(C M G \_9\right)$ or none $\left(C M G \_10-11\right)$. As shown in Table 1, the distillation yields differed significantly among the analyzed resins, providing an average of $14.7 \mathrm{~mL} / \mathrm{kg}$ of essential oil.

Moreover, in the case of CMG_6, the yield was found below the limit set by the monograph, with CMG_1 and 2 barely surpassing it. Since these samples were collected at the same period as two of the highest CMO-producing resins (CMG_3,5), it seems that other parameters such as the age of the tree or climatic conditions might play a significant role in essential oil content. Nonetheless, it was verified that ageing decreases CMO yield, leading to almost none or traces production after a long period of storage. Interestingly, according to Papanicolaou et al., the loss of essential oil during storage was attributed mainly to the transformation of volatiles to non-volatiles and, to a lesser degree, to evaporation [49]. Consequently, distillation yield in itself does not constitute an adequate marker of quality, and the proposed levels might need to be reconsidered. However, given that our results on the loss of volatiles during ageing and the average calculated yield corroborated with those reported elsewhere [50,51], we consider that essential oil yield might provide meaningful information that should be examined in conjunction with findings from other techniques. 
To our knowledge, in previous studies investigating this aspect, the number of analyzed samples was significantly low and, therefore, a direct comparison is infeasible [38].

Table 1. Hydrodistillation yields, performed according to the Ph. Eur. instructions.

\begin{tabular}{cccc}
\hline Collection Time (month/year) & Resin & Essential Oil & Yield (mL/kg) \\
\hline $01 / 2020$ & CMG_1 & CMO_1 & 11.9 \\
$01 / 2020$ & CMG_2 & CMO_2 & 10.3 \\
$02 / 2020$ & CMG_3 & CMO_3 & 23.4 \\
$02 / 2020$ & CMG_4 & CMO_4 & 19.5 \\
$02 / 2020$ & CMG_5 & CMO_5 & 24.8 \\
$06 / 2020$ & CMG_6 & CMO_6 & 9.9 \\
$06 / 2020$ & CMG_7 & CMO_7 & 14.3 \\
$11 / 2018$ & CMG_8 & CMO_8 & 3.5 \\
& Minimum & & 3.5 \\
& Maximum & & 24.8 \\
2010 & Average \pm SD & & $14.7 \pm 7.3$ \\
\hline 2010 & CMG_9 & CMO_9 & traces \\
\hline & CMG_10 & CMO_10 & - \\
\hline
\end{tabular}

${ }^{1} \mathrm{SD}=$ Standard Deviation.

\subsection{HPTLC Profiling}

Apart from distillation yields, a TLC method was also described in the Ph. Eur. monograph for the identification of CMG, accompanied by a visual inspection of substances considering the color and the shape of certain zones. Eugenol and borneol were used as reference compounds. In the current study, the Ph. Eur. method was used for the analysis of all 11 CMG samples, together with the respective CMOs, utilizing an HPTLC approach [44]. Additionally, an in-house elution method was developed for the profiling of both sample types (Figure 1).

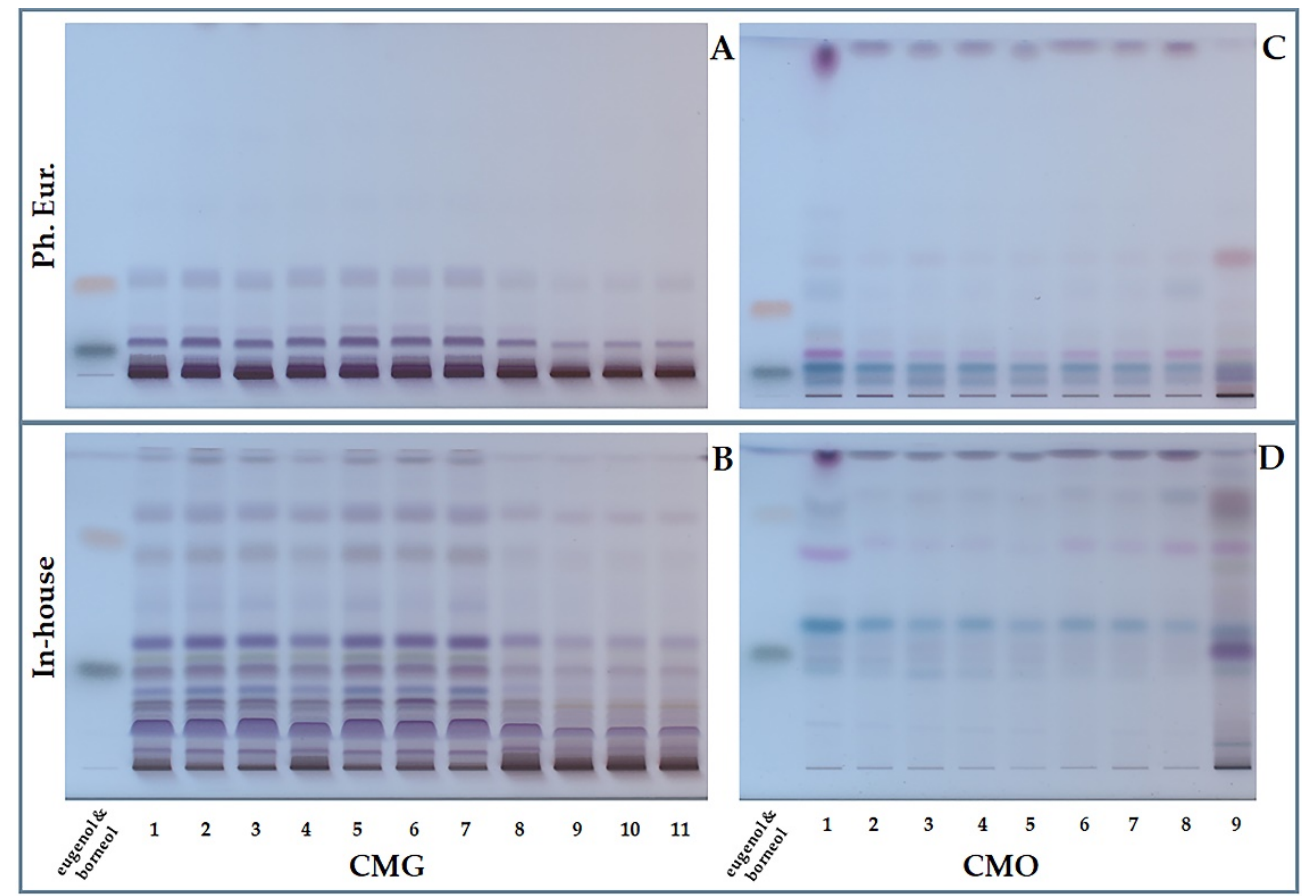

Figure 1. HPTLC chromatograms of Chios Mastic Gum (CMG) (A,B) and Chios Mastic Oil (CMO) (C,D) samples developed with the Ph. Eur. (A,C) and in-house (B,D) methods. Detection at visible light after spraying with vanillin reagent. 
According to the Ph. Eur. monograph, six zones of different coloring after spraying were evaluated and compared with the reference standards indicating the resin's identity. As shown in Figure 1A, the solvent system proposed by the Ph. Eur. was not suitable for profiling and compound monitoring, since most of the constituents were concentrated on the baseline together with the poly- $\beta$-myrcene polymer (dark brown). The same remark could be made for the CMO samples (Figure 1C). In order to resolve this issue, the development of an in-house method was deemed necessary. To that end, different solvent systems (e.g., toluene/ethyl acetate/heptane/formic acid 80:20:10:3, cyclohexane/diisopropyl ether/acetic acid 60:40:10, dichloromethane/methanol 98:2) and methanol for resin dilution were tested for the development of a suitable HPTLC method (data not shown). Moreover, the dilution of the resin in different solvents, i.e., dichloromethane, methanol, acetone, and acetonitrile, were also tested. Finally, dichloromethane/methanol 98:2 as an elution system was selected as the most suitable, and dichloromethane for resin dilution was found to be the most appropriate solvent. Furthermore, the initial concentration of the samples was reduced to $10 \mathrm{mg} / \mathrm{mL}$ for crude mastic powder (compared to $100 \mathrm{mg} / \mathrm{mL}$ proposed by Ph. Eur.) in order to achieve an improved sample dilution and, therefore, an enhanced separation and a more rigid and uniform elution of constituents. Lastly, filtration of samples prior to application was omitted, ensuring a greater metabolite coverage. As observed in Figure 1B,D, with the elution system employed, the separation of the compounds was more efficient, the resolution was greatly improved, and even minor qualitative and/or quantitative alterations could be detected.

Based on the HPTLC data, a comparison between the fresh and aged samples could be made regardless of the method used, even if, with the in-house method, the assessment was considerably more straightforward. Figures S1-S4, present the different chemical profiles between the fresh and aged collections in 254 and $366 \mathrm{~nm}$. The effect of ageing could be observed in both CMG and CMO samples. In the aged resin samples in particular (CMG_9-11), the absence of zones and/or quantitative decrease was clearly evident, possibly indicating the instability of the resin over time and the decomposition of numerous constituents. Moreover, it seems that the formation of $\beta$-myrcene polymer was favored over time as it was manifested by the obvious relative intensification of the dark brown zone at the baseline. Poly- $\beta$-myrcene, which is derived from myrcene polymerization present in $\mathrm{CMO}$, undergoes further oxidation reactions affording diverse oxidation products [52]. In general, according to Behr et al., the storage of myrcene is a difficult task since it polymerizes spontaneously at room temperature. One-third is lost by polymerization in a 3-month period leading to a higher viscosity index and the formation of peroxides [53]. The addition of vitamin $\mathrm{E}$ has been suggested as a means of impeding polymerization and oxidation phenomena [49], while other agents have also been proposed, such as $0.1 \%$ p-tert-butylcatechol and a mixture of $0.05 \%$ p-tert-butylcatechol and $0.05 \%$ butylhydroxyanisol [53]. This observation was also evident in the profiles of the CMO samples, where polymer formation along with the appearance of several new zones of increased polarity, clearly sets the oil produced from the 10-year-old resin (CMO_9) apart from the rest. In fact, $\mathrm{CMO}$ could be suggested as an even better substrate for ageing detection, given that its profile presents many more differences with fresh and slightly aged samples compared to its respective crude resin.

Finally, it is worth mentioning that despite the importance of CMO's chemical composition for the quality control of the resin, a fact recognized even by the Ph. Eur., the number of studies aiming to assess the effect of ageing on the essential oil's yield and profile is quite limited and outdated, while the investigated storage period is usually restricted to a few months [38,49]. In addition, to our knowledge, there is no HPTLC methodology in the literature for $\mathrm{CMG}$ and/or CMO profiling, an alternative to the Ph. Eur. monograph. It is important to state that given that the technique is the advanced form of Thin-Layer Chromatography (TLC), automation, low operating cost, improved application of the samples, higher separation, resolution, data acquisition and processing, faster analysis time, and lower volumes of mobile phase are ensured [54]. Moreover, HPTLC is characterized as a 
state-of-the-art method and a useful analytical tool in the case of complex mixtures, e.g., plant extracts [55].

\subsection{GC-MS Analysis}

Amongst analytical techniques, GC-MS has been almost exclusively used for the chemical characterization of CMO as well as CMG [50,56,57]. More precisely, GC-MS constitutes the method of choice as it is often employed for the detection of adulteration phenomena in the oil and, generally, for its quality assessment [51]. In the current study, 8 samples of essential oils produced from fresh and slightly aged resins (CMO_1-8) were analyzed. Due to the minimal production of essential oils from resins aged 10 years and more, only one sample, namely CMG_9, provided oil in an adequate quantity (CMO_9) and was, therefore, forwarded for analysis. In Figure 2, superimposed total ion chromatograms (TIC) of representative samples (CMO_1, CMO_8, and CMO_9) are presented, clearly demonstrating the chemical transformations taking place over time.

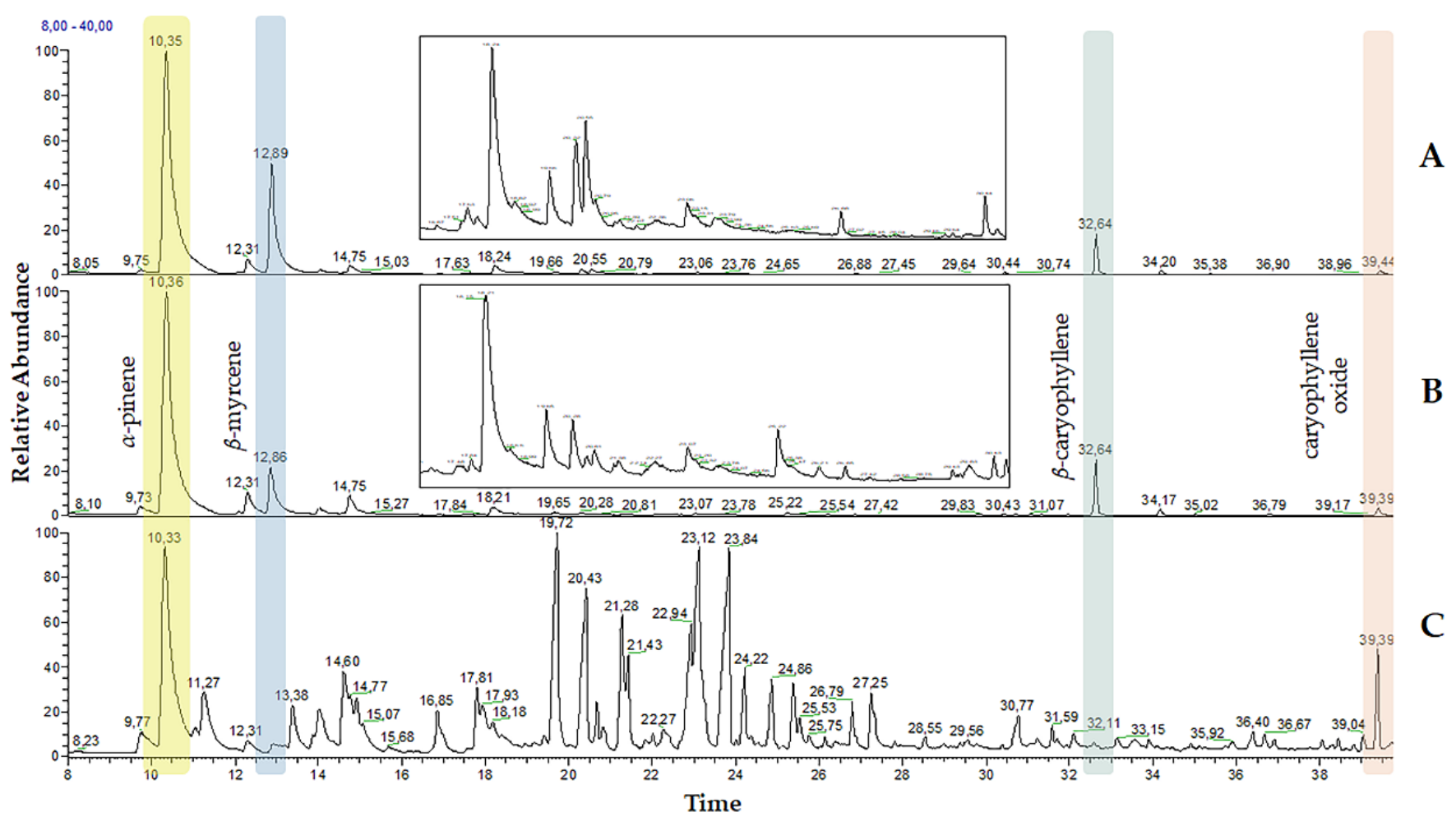

Figure 2. GC-MS chromatograms of Chios Mastic Oils (CMOs) obtained from (A) a fresh (CMO_1), (B) a 2-year-old (CMO_8) and (C) a 10-year-old resin (CMO_9).

Based on the GC-MS data explained in detail in Table 2, 33 compounds were identified in fresh CMO samples (CMO_1-7) (97.69\%) together with 7 non-identified $(1.10 \%)$.

The main categories of metabolites found in fresh samples (CMO_1-7) were monoterpene hydrocarbons $(86.01 \%)$, oxygenated monoterpenes and benzenoids $(4.60 \%)$, sesquiterpene hydrocarbons $(4.99 \%)$, oxygenated sesquiterpenes $(0.63 \%)$, and diterpene hydrocarbons $(1.47 \%)$. The oil produced from a 10-year-old resin (CMO_9) demonstrated a significantly different profile verifying the HPTLC observations and 25 compounds were identified in total (70.85\%). A more comprehensive annotation of a fresh and aged sample is presented in Figure S5. Even from a preliminary inspection of the available chromatograms, it is obvious that ageing has a profound effect on the composition of $\mathrm{CMO}$, and hence it shall be discussed in greater detail in the following Section 3.4. 
Table 2. GC-MS analysis of the essential oil composition of fresh CMO samples (CMO_1-7).

\begin{tabular}{|c|c|c|c|c|c|c|c|}
\hline $\mathbf{A} / \mathbf{A}$ & $\operatorname{Rt}(\min )^{1}$ & Compound & $\begin{array}{l}\text { Molecular } \\
\text { Formula }\end{array}$ & $\mathrm{MW}(\mathrm{g} / \mathrm{mol})^{2}$ & $\begin{array}{c}\text { Main Fragments } \\
\text { (Descending Intensity) }\end{array}$ & $\mathbf{R I}^{3}$ & $\mathrm{IM}^{4}$ \\
\hline 1 & 9.75 & N/I_C01 & $\mathrm{C}_{10} \mathrm{H}_{16}$ & 136.23 & $\begin{array}{c}93,67,49,41,84,79,108 \\
121,136\end{array}$ & - & MS \\
\hline 2 & 10.36 & $\alpha$-Pinene & $\mathrm{C}_{10} \mathrm{H}_{16}$ & 136.23 & $93,77,105,121,67,41,53,136$ & - & MS \\
\hline 3 & 12.10 & Sabinene & $\mathrm{C}_{10} \mathrm{H}_{16}$ & 136.23 & $93,77,41,136,121,105$ & - & MS \\
\hline 4 & 12.31 & $\beta$-Pinene & $\mathrm{C}_{10} \mathrm{H}_{16}$ & 136.23 & $93,69,41,79,121,136$ & - & MS \\
\hline 5 & 12.88 & $\beta$-Myrcene & $\mathrm{C}_{10} \mathrm{H}_{16}$ & 136.23 & $69,93,41,79,53,121,107,136$ & - & MS \\
\hline 6 & 14.06 & $\begin{array}{l}o \text {-Methyl- } \\
\text { anisole }\end{array}$ & $\mathrm{C}_{8} \mathrm{H}_{10} \mathrm{O}$ & 122.16 & $122,107,77,91,51,69,41,83$ & - & MS \\
\hline 7 & 14.76 & $D$-Limonene & $\mathrm{C}_{10} \mathrm{H}_{16}$ & 136.23 & $68,93,79,107,53,121,41,136$ & - & MS \\
\hline 8 & 16.22 & N/I_C02 & $\mathrm{C}_{10} \mathrm{H}_{18} \mathrm{O}$ & 154.25 & $\begin{array}{c}49,84,93,41,69,77,121 \\
107,136\end{array}$ & - & MS \\
\hline 9 & 16.88 & N/I_C03 & $\mathrm{C}_{10} \mathrm{H}_{18} \mathrm{O}$ & 154.25 & $\begin{array}{c}49,84,93,69,41,79,107,122 \\
137,152\end{array}$ & - & MS \\
\hline 10 & 17.64 & Terpinolene & $\mathrm{C}_{10} \mathrm{H}_{16}$ & 136.23 & $93,121,136,69,79,41,105,152$ & - & MS \\
\hline 11 & 17.86 & Camphenol & $\mathrm{C}_{10} \mathrm{H}_{16} \mathrm{O}$ & 152.23 & $93,108,67,41,79,121,137,152$ & - & MS \\
\hline $12 \& 13$ & 18.25 & $\begin{array}{c}\text { Perillene \& } \\
\alpha \text {-Linalool }\end{array}$ & $\begin{array}{c}\mathrm{C}_{10} \mathrm{H}_{14} \mathrm{O} \& \\
\mathrm{C}_{10} \mathrm{H}_{18} \mathrm{O}\end{array}$ & $150.22 \& 154.25$ & $\begin{array}{c}69,71,41,93,55,81,150,121 \\
107,135\end{array}$ & - & MS \\
\hline 14 & 18.81 & N/I_C04 & $\mathrm{C}_{10} \mathrm{H}_{18} \mathrm{O}$ & 154.25 & $\begin{array}{c}69,71,93,41,55,84,121,150 \\
107,136,154\end{array}$ & - & MS \\
\hline 15 & 19.67 & $\begin{array}{c}\alpha- \\
\text { Campholenal }\end{array}$ & $\mathrm{C}_{10} \mathrm{H}_{16} \mathrm{O}$ & 152.23 & $108,93,67,41,81,150,119,136$ & - & MS \\
\hline 16 & 20.30 & Pinocarveol & $\mathrm{C}_{10} \mathrm{H}_{16} \mathrm{O}$ & 152.23 & $\begin{array}{c}55,92,69,41,83,109,119 \\
134,150\end{array}$ & - & MS \\
\hline 17 & 20.57 & Cis-Verbenol & $\mathrm{C}_{10} \mathrm{H}_{16} \mathrm{O}$ & 152.23 & $109,41,81,91,69,119,150,137$ & - & MS \\
\hline 18 & 21.40 & N/I_C05 & $\mathrm{C}_{11} \mathrm{H}_{18}$ & 150.26 & $\begin{array}{c}49,84,69,41,108,93,135 \\
122,150\end{array}$ & - & MS \\
\hline 19 & 22.33 & Verbenol & $\mathrm{C}_{10} \mathrm{H}_{16} \mathrm{O}$ & 152.23 & $\begin{array}{c}59,94,79,69,83,41,109,119 \\
136,150\end{array}$ & - & MS \\
\hline 20 & 23.07 & Myrtenal & $\mathrm{C}_{10} \mathrm{H}_{14} \mathrm{O}$ & 150.22 & $79,107,91,41,67,119,135,150$ & 1203.0 & RI, MS \\
\hline 21 & 23.81 & Verbenone & $\mathrm{C}_{10} \mathrm{H}_{14} \mathrm{O}$ & 150.22 & $107,91,79,135,67,41,150,122$ & 1220.5 & RI, MS \\
\hline 22 & 26.27 & N/I_C06 & $\mathrm{C}_{10} \mathrm{H}_{16} \mathrm{O}$ & 152.23 & $\begin{array}{c}93,69,49,41,84,79,136,164 \\
121,109,150\end{array}$ & - & MS \\
\hline 23 & 26.89 & Bornyl acetate & $\mathrm{C}_{12} \mathrm{H}_{20} \mathrm{O}_{2}$ & 196.29 & $\begin{array}{c}95,43,121,136,108,67,55,80 \\
154,196\end{array}$ & 1291.6 & RI, MS \\
\hline 24 & 29.46 & N/I_C07 & $\mathrm{C}_{15} \mathrm{H}_{26} \mathrm{O}$ & 222.37 & $\begin{array}{c}105,161,119,49,91,69,41,84 \\
58,204,148,133\end{array}$ & - & MS \\
\hline 25 & 29.64 & $\alpha$-Longipinene & $\mathrm{C}_{15} \mathrm{H}_{24}$ & 204.35 & $\begin{array}{c}119,105,93,133,69,41,55,79 \\
204,161,152,189\end{array}$ & 1354.4 & RI, MS \\
\hline 26 & 30.46 & $\alpha$-Ylangene & $\mathrm{C}_{15} \mathrm{H}_{24}$ & 204.35 & $\begin{array}{c}105,119,93,161,41,69,79,55 \\
133,204,189,148\end{array}$ & 1373.0 & RI, MS \\
\hline 27 & 30.76 & $\alpha$-Copaene & $\mathrm{C}_{15} \mathrm{H}_{24}$ & 204.35 & $\begin{array}{c}105,119,161,93,69,81,41 \\
148,133,204,189\end{array}$ & 1379.6 & RI, MS \\
\hline 28 & 31.10 & $\beta$-Bourbonene & $\mathrm{C}_{15} \mathrm{H}_{24}$ & 204.35 & $\begin{array}{c}81,123,91,105,41,69,161 \\
148,133,204\end{array}$ & 1387.3 & RI, MS \\
\hline
\end{tabular}


Table 2. Cont.

\begin{tabular}{|c|c|c|c|c|c|c|c|}
\hline A/A & $\operatorname{Rt}(\min )^{1}$ & Compound & $\begin{array}{l}\text { Molecular } \\
\text { Formula }\end{array}$ & $\operatorname{MW}(\mathrm{g} / \mathrm{mol})^{2}$ & $\begin{array}{c}\text { Main Fragments } \\
\text { (Descending Intensity) }\end{array}$ & $\mathrm{RI}^{3}$ & $\mathrm{IM}^{4}$ \\
\hline 29 & 31.33 & $\beta$-Elemene & $\mathrm{C}_{15} \mathrm{H}_{24}$ & 204.35 & $\begin{array}{c}93,81,69,148,41,105,121 \\
133,161,189,176,204\end{array}$ & 1392.7 & RI, MS \\
\hline 30 & 31.98 & Isocaryophyllene & $\mathrm{C}_{15} \mathrm{H}_{24}$ & 204.35 & $\begin{array}{c}93,69,133,105,41,79,55,148 \\
119,161,189,175,204\end{array}$ & 1407.6 & RI, MS \\
\hline 31 & 32.65 & $\begin{array}{c}\beta- \\
\text { Caryophyllene }\end{array}$ & $\mathrm{C}_{15} \mathrm{H}_{24}$ & 204.35 & $\begin{array}{c}93,133,105,69,79,41,55,120 \\
147,161,189,175,204\end{array}$ & 1423.9 & RI, MS \\
\hline 32 & 34.21 & $\alpha$-Humulene & $\mathrm{C}_{15} \mathrm{H}_{24}$ & 204.35 & $\begin{array}{c}93,121,80,107,147,67,41,53 \\
204,136,189,161,175\end{array}$ & 1461.1 & RI, MS \\
\hline 33 & 35.11 & $\alpha$-Muurolene & $\mathrm{C}_{15} \mathrm{H}_{24}$ & 204.35 & $\begin{array}{c}105,161,91,119,79,133,69 \\
41,204,55,148,189,178\end{array}$ & 1482.3 & RI, MS \\
\hline 34 & 35.39 & D-Germacrene & $\mathrm{C}_{15} \mathrm{H}_{24}$ & 204.35 & $\begin{array}{c}161,105,91,79,119,41,148 \\
133,69,204,178\end{array}$ & 1489.0 & RI, MS \\
\hline 35 & 39.46 & $\begin{array}{l}\text { Caryophyllene } \\
\text { oxide }\end{array}$ & $\mathrm{C}_{15} \mathrm{H}_{24} \mathrm{O}$ & 220.35 & $\begin{array}{c}79,93,41,69,107,55,121,135 \\
147,161,178,187,205,220\end{array}$ & 1591.2 & RI, MS \\
\hline 36 & 40.68 & $\begin{array}{l}\alpha \text {-Humulene } \\
\text { epoxide II }\end{array}$ & $\mathrm{C}_{15} \mathrm{H}_{24} \mathrm{O}$ & 220.35 & $\begin{array}{c}109,67,96,138,43,55,81,123 \\
178,148,164,205,191,220\end{array}$ & - & MS \\
\hline 37 & 50.40 & $\begin{array}{c}p \text { - } \\
\text { Camphorene/ } \\
\text { Dimyrcene }\end{array}$ & $\mathrm{C}_{20} \mathrm{H}_{32}$ & 272.47 & $\begin{array}{c}69,41,93,105,55,119,79,133 \\
229,147,187,161,272,175 \\
202,216,243,257\end{array}$ & - & MS \\
\hline 38 & 51.15 & Dimyrcene & $\mathrm{C}_{20} \mathrm{H}_{32}$ & 272.47 & $\begin{array}{c}69,93,41,105,55,79,121,187 \\
147,229,133,159,203,272 \\
175,257,215,243\end{array}$ & - & MS \\
\hline 39 & 52.26 & $\begin{array}{c}m- \\
\text { Camphorene/ } \\
\text { Dimyrcene }\end{array}$ & $\mathrm{C}_{20} \mathrm{H}_{32}$ & 272.47 & $\begin{array}{c}69,41,91,105,119,79,133,55 \\
147,229,203,161,187,272 \\
257,173,216,243\end{array}$ & - & MS \\
\hline 40 & 53.58 & Dimyrcene & $\mathrm{C}_{20} \mathrm{H}_{32}$ & 272.47 & $\begin{array}{c}69,93,41,105,79,133,119,55 \\
229,147,203,161,187,272 \\
257,175\end{array}$ & - & MS \\
\hline
\end{tabular}

${ }^{1} \mathrm{Rt}=$ Retention time; ${ }^{2} \mathrm{MW}=$ Molecular Weight; ${ }^{3} \mathrm{RI}=$ Retention Indices calculated against $\mathrm{n}$-alkanes; ${ }^{4} \mathrm{IM}=$ Identification Method.

Regarding the fresh samples' chemical composition (CMO_1-7), the dominant compounds are $\alpha$-pinene (Rt $10.3 \mathrm{~min}$ ) ranging from 56.4 to $73.0 \%$ (avg. $64.8 \%$ ) and $\beta$-myrcene (Rt $12.8 \mathrm{~min}$ ) ranging from 12.6 to $19.9 \%$ (avg. $16.4 \%$ ), verifying available information $[15,51]$. Other compounds detected in significant levels included $\beta$-pinene (2.47$3.08 \%)$, limonene (1.24-1.98\%), perillene coeluting with $\alpha$-linalool $(0.84-2.53 \%)$, and $\beta$ caryophyllene (2.21-6.38\%). Interestingly, perillene has only been reported in two studies thus far $[11,51]$ while the compounds camphor, 1-ethenyl-2,4-dimethylbenzene or 1-methyl-4-(2-propenyl)-benzene, $\beta$-methyl-cinnamaldehyde, trimethyl-hydroquinone, 3,8,8-trimethyl-1,2,3,4,5,6,7,8-octahydro-2-naphthalenyl methyl acetate, and 4-acetyl-1methylcyclohexene are reported for the first time in the 10-year old CMO.

The major compounds found in mastic's essential oil, $\alpha$-pinene and $\beta$-myrcene have been proposed in the past as quality markers for $\mathrm{CMO}$ [51], however, most available studies did not follow a standardized methodology for the resin's distillation and/or the storage period was not mentioned. Therefore, a direct comparison of the calculated metabolites content was not possible, especially when the geographical origin of the starting material was not clear [26] or market samples of CMO were analyzed [51]. As a consequence, the reported levels of those two major compounds varied considerably in the existing literature, i.e., for $\alpha$-pinene between $30-90 \%$ and for $\beta$-myrcene between 1-60\% [50,58,59]. In fact, it appears that sample origin is so crucial to the essential oil's composition that in some cases of essential oil acquired from a different Pistacia lentiscus variety, $\beta$-myrcene was reported 
at very low levels $(<4 \%)$ or it was completely absent $[26,60,61]$. Impressively, in one case, $\alpha$-copaene is mentioned as one of the major compounds, while according to our findings it constitutes one of the minor constituents [62].

We hereby have to note that despite the existence of a limited number of studies assessing CMO's chemical composition, to our knowledge, there is only one previous research work by Paraschos and colleagues where a considerable number of authentic mastic oil samples have been analyzed similar to the current study [51]. Nevertheless, even in this comprehensive effort, the samples were not acquired through a controlled laboratory process, instead, they were commercial specimens provided by the official producers. In that scope, the present work attempts to narrow down the proposed limits of marker compounds in CMO, following a standardized methodology for its distillation, as proposed by an official authority (Ph. Eur.).

\subsection{Essential Oil Ageing}

Ageing together with storage are critical for quality assessment; hence monitoring of marker compounds during the ageing process is deemed essential. In the current study, the ageing effect on the resin and the produced essential oils was assessed in samples collected 2 and 10 years prior to analysis with the view to provide further insight on the chemical transformations taking place in mastic samples overtime. Table 3 summarizes the qualitative and/or quantitative differences in specific constituents between fresh and aged samples.

Table 3. CMO chemical composition in fresh (CMO_1-7), aged for 2 years (CMO_8) and aged for 10 years (CMO_9) samples analyzed.

\begin{tabular}{|c|c|c|c|c|}
\hline Compounds & $\begin{array}{c}(\text { Min-Max) \% in } \\
\text { Fresh Samples }(n=7)\end{array}$ & $\begin{array}{c}\text { Average } \% \pm \text { SD in } \\
\text { Fresh Samples }(n=7)\end{array}$ & $\begin{array}{l}\% \text { in the 2-Year-Old } \\
\text { Sample }(n=1)\end{array}$ & $\begin{array}{c}\% \text { in the } 10 \text {-Year-Old } \\
\text { Sample }(n=1)\end{array}$ \\
\hline Monoterpene hydrocarbons & $79.40-91.15$ & $86.01 \pm 4.37$ & 81.96 & 13.2 \\
\hline $\begin{array}{c}\text { Oxygenated monoterpenes }{ }^{1} \mathcal{E} \\
\text { Benzenoids }\end{array}$ & $3.75-6.25$ & $4.60 \pm 0.78$ & 4.35 & 52.51 \\
\hline Sesquiterpene hydrocarbons & $2.84-7.94$ & $4.99 \pm 1.96$ & 5.91 & 0.08 \\
\hline Oxygenated sesquiterpenes & $0.29-0.96$ & $0.63 \pm 0.26$ & 0.90 & 1.91 \\
\hline Diterpene hydrocarbons & $0.29-2.62$ & $1.47 \pm 0.89$ & 3.23 & - \\
\hline Ketones & & - & - & 3.23 \\
\hline Total identified & $96.12-98.43$ & $97.69 \pm 0.79$ & 96.35 & 70.85 \\
\hline Total non-identified & $0.76-1.66$ & $1.10 \pm 0.31$ & 1.98 & 29.00 \\
\hline Compounds & $\begin{array}{c}(\text { Min-Max) } \% \text { in } \\
\text { Fresh Samples }(n=7)\end{array}$ & $\begin{array}{c}\text { Average } \% \pm \text { SD in } \\
\text { Fresh Samples }(n=7)\end{array}$ & $\begin{array}{l}\% \text { in the } 2-\text { Year-Old } \\
\text { Sample }(n=1)\end{array}$ & $\begin{array}{c}\% \text { in the } 10-\text { Year-Old } \\
\text { Sample }(n=1)\end{array}$ \\
\hline \multicolumn{5}{|c|}{ Monoterpene Hydrocarbons } \\
\hline$\alpha$-Pinene & $56.42-72.99$ & $64.83 \pm 5.78$ & 65.65 & 12.00 \\
\hline$\beta$-Pinene & $2.47-3.08$ & $2.75 \pm 0.25$ & 3.81 & 0.45 \\
\hline$\beta$-Myrcene & 12.6- 19.94 & $16.40 \pm 3.17$ & 8.90 & - \\
\hline Sabinene & $0.18-0.3$ & $0.23 \pm 0.04$ & 0.28 & - \\
\hline D-Limonene & $1.24-1.98$ & $1.66 \pm 0.32$ & 3.24 & - \\
\hline Terpinolene & $0.11-0.2$ & $0.15 \pm 0.04$ & 0.08 & - \\
\hline Camphene & - & - & - & 0.75 \\
\hline \multicolumn{5}{|c|}{ Oxygenated Monoterpenes ${ }^{1} \mathcal{E}$ Benzenoids ${ }^{2}$} \\
\hline Perillene $^{1} \& \alpha$-Linalool ${ }^{1}$ & $0.84-2.53$ & $1.68 \pm 0.64$ & 1.73 & - \\
\hline Camphenol $^{1}$ & $0.06-0.09$ & $0.08 \pm 0.01$ & 0.07 & - \\
\hline$\alpha$-Campholenal ${ }^{1}$ & $0.33-0.47$ & $0.39 \pm 0.05$ & 0.42 & 6.32 \\
\hline Pinocarveol ${ }^{1}$ & $0.31-0.72$ & $0.50 \pm 0.14$ & 0.29 & 5.16 \\
\hline cis-Verbenol $^{1}$ & $0.3-1.05$ & $0.61 \pm 0.25$ & 0.2 & - \\
\hline Verbenol $^{1}$ & $0.15-0.31$ & $0.21 \pm 0.057$ & 0.17 & - \\
\hline Verbenone $^{1}$ & $0.07-0.22$ & $0.13 \pm 0.059$ & 0.07 & 7.21 \\
\hline Bornyl acetate $^{1}$ & $0.07-0.2$ & $0.11 \pm 0.046$ & 0.06 & 0.98 \\
\hline Campholene group ${ }^{1}$ & - & - & - & 4.62 \\
\hline
\end{tabular}


Table 3. Cont.

\begin{tabular}{|c|c|c|c|c|}
\hline Compounds & $\begin{array}{l}(\text { Min-Max) } \% \text { in } \\
\text { Fresh Samples }(n=7)\end{array}$ & $\begin{array}{c}\text { Average } \% \pm \text { SD in } \\
\text { Fresh Samples }(n=7)\end{array}$ & $\begin{array}{l}\% \text { in the } 2 \text {-Year-Old } \\
\text { Sample }(n=1)\end{array}$ & $\begin{array}{c}\% \text { in the } 10 \text {-Year-Old } \\
\text { Sample }(n=1)\end{array}$ \\
\hline \multicolumn{5}{|c|}{ Oxygenated Monoterpenes ${ }^{1} \mathcal{E}$ Benzenoids ${ }^{2}$} \\
\hline Camphor ${ }^{1}$ & - & - & - & 0.78 \\
\hline $\begin{array}{l}\text { 3,6,6-Trimethyl } \\
\text { norpinan-2-one }{ }^{1} \& \\
\text { Pinocarvone }^{1}\end{array}$ & - & - & - & 4.99 \\
\hline cis-3-Pinanone ${ }^{1}$ & - & - & - & 0.27 \\
\hline $\begin{array}{c}\text { cis-Carveol }{ }^{1} \\
\text { 1-Ethenyl-2,4- } \\
\text { dimethylbenzene or }\end{array}$ & - & - & - & 1.47 \\
\hline $\begin{array}{c}\text { 1-Methyl-4-(2-propenyl)- } \\
\text { benzene }{ }^{2} \& \\
\text { o-Methyl-anisole }\end{array}$ & $0.36-0.84$ & $0.60 \pm 0.16$ & 1.14 & 1.93 \\
\hline o-, p- \& m-Cymene ${ }^{2}$ & - & - & - & 5.30 \\
\hline$\beta$-Methyl-cinnamaldehyde ${ }^{2}$ & - & - & - & 0.15 \\
\hline Myrtenal ${ }^{1} \&$ p-Cymen-8-ol ${ }^{2}$ & $0.22-0.39$ & $0.28 \pm 0.058$ & 0.2 & 11.11 \\
\hline $\begin{array}{c}\text { Carvone }^{1} \& \\
\text { Trimethyl-hydroquinone }^{2}\end{array}$ & - & - & - & 2.22 \\
\hline
\end{tabular}

\begin{tabular}{|c|c|c|c|c|}
\hline \multicolumn{5}{|c|}{ Sesquiterpene Hydrocarbons } \\
\hline$\beta$-Caryophyllene & $2.21-6.38$ & $4.13 \pm 1.53$ & 4.74 & - \\
\hline$\alpha$-Humulene & $0.28-0.91$ & $0.54 \pm 0.22$ & 0.69 & - \\
\hline$\alpha$-Longipinene & $0.01-0.07$ & $0.03 \pm 0.02$ & 0.02 & - \\
\hline$\alpha$-Ylangene & $0.04-0.16$ & $0.10 \pm 0.04$ & 0.08 & 0.08 \\
\hline$\alpha$-Copaene & $0.02-0.08$ & $0.05 \pm 0.02$ & 0.06 & - \\
\hline$\beta$-Bourbonene & $0.01-0.07$ & $0.04 \pm 0.02$ & 0.07 & - \\
\hline$\beta$-Elemene & $0.01-0.09$ & $0.04 \pm 0.03$ & 0.07 & - \\
\hline Isocaryophyllene & $0.02-0.11$ & $0.06 \pm 0.03$ & 0.07 & - \\
\hline a-Muurolene & $0.03-0.09$ & $0.05 \pm 0.02$ & 0.08 & - \\
\hline D-Germacrene & $0.05-0.1$ & $0.06 \pm 0.02$ & 0.03 & - \\
\hline \multicolumn{5}{|c|}{ Oxygenated Sesquiterpenes } \\
\hline Caryophyllene oxide & $0.27-0.89$ & $0.58 \pm 0.24$ & 0.82 & 1.63 \\
\hline $\begin{array}{c}\alpha \text {-Humulene epoxide II } \\
\text { 3,8,8-Trimethyl- }\end{array}$ & $0.02-0.07$ & $0.05 \pm 0.02$ & 0.08 & - \\
\hline $\begin{array}{c}1,2,3,4,5,6,7,8-\text { octahydro-2- } \\
\text { naphthalenyl methyl } \\
\text { acetate }\end{array}$ & - & - & - & 0.28 \\
\hline \multicolumn{5}{|c|}{ Ketones } \\
\hline $\begin{array}{l}\text { 4-Acetyl-1- } \\
\text { methylcyclohexene }\end{array}$ & - & - & - & 1.53 \\
\hline 2-Undecanone & - & - & - & 1.70 \\
\hline
\end{tabular}

${ }^{1}$ Oxygenated monoterpenes; ${ }^{2}$ Benzenoids.

Even from a preliminary analysis of the results, it is obvious that CMG undergoes severe alterations to its chemical composition. In more detail, it seems that monoterpene hydrocarbons decrease slightly in the 2-year storage (81.96\%) and significantly in the 10 years one (13.2\%). Oxygenated monoterpenes and benzenoids have similar rates over the 2-year period, but in the 10-year-old sample, they constitute more than half of the oil's composition (52.5\%); thus, chemical processes such as oxidation are implied. Sesquiterpene hydrocarbons appeared to be almost absent in the 10-year aged sample, whilst their oxygenated counterparts were higher compared to the fresh samples. In the only study 
investigating the ageing in a 3-year storage period, there was only a slight decline in the monoterpene hydrocarbons, while all the other categories exhibited similar rates [38].

Investigating individual compounds, it is obvious that the fresh collections contain $\alpha$-pinene and $\beta$-myrcene at the highest rates. It has been reported that under thermal oxidation conditions, $\alpha$-pinene and $\beta$-pinene can be transformed to oxygenated monoterpenes $[63,64]$. $\alpha$-Pinene seems to be unaffected in the collection aged for 2 years $(65.7 \%)$, verifying an existing study reporting a 3-year storage [38]. However, its content was found significantly lower (12.0\%) in the sample aged over a 10-year period. Evidently, as time goes by, both compounds suffer from a definitive loss in content, however, $\beta$-myrcene, clearly stands out as the one most affected by long storage periods. As a matter of fact, in the collection of 2018, i.e., CMG_8, which produced little oil (CMO_8), $\beta$-myrcene was found at a lower rate in contrast to the other fresh collections, while in the oil produced from the 10 -year aged collection, $\beta$-myrcene was completely absent. Therefore, $\beta$-myrcene could be suggested as a marker for ageing as it clearly demonstrates a gradual decrease over time [38]. Indeed, the ratios of $\beta$-myrcene $/ \alpha$-pinene and $\beta$-pinene $/ \beta$-myrcene have been previously proposed as quality markers for CMO [38,51]. According to our findings presented in detail in Table S1, the ratio of $\beta$-myrcene/ $\alpha$-pinene was more suitable for the qualitative evaluation of CMO's ageing process, as it displayed a more evident decrease in oils procured from aged resins and a low SD amongst samples of fresh collection. In fact, when this rate equals zero, as in the case of the 10-year old collection, it can be safely assumed that the oil is entirely aged. The ratios calculated herein coincide with those previously reported [11,38,51], with $\beta$-myrcene / $\alpha$-pinene ranging from $0.14-0.35$ and $\beta$-pinene $/ \beta$-myrcene from $0.13-0.43$.

Apart from the gradual degradation of marker-compounds such as $\alpha$-pinene and $\beta$-myrcene, other compounds were also decreased over time, with the most characteristic being $\beta$-caryophyllene (Rt $32.6 \mathrm{~min}$ ), giving its place to its oxidized product, caryophyllene oxide (Rt $39.4 \mathrm{~min}$ ). In the same context, oxidized products of monoterpenes such as pinocarveol (Rt $20.4 \mathrm{~min}$ ) and verbenone (Rt $23.8 \mathrm{~min}$ ) dominated the profile of the 10-year aged sample. Based on our data, these compounds, along with $\alpha$-campholenal (Rt $19.7 \mathrm{~min}$ ) were detected $<1 \%$ in fresh samples, whereas pinocarvone (Rt $21.3 \mathrm{~min}$ ) and cis-carveol (Rt $24.2 \mathrm{~min}$ ) were only detected in the aged sample (Figure 3).

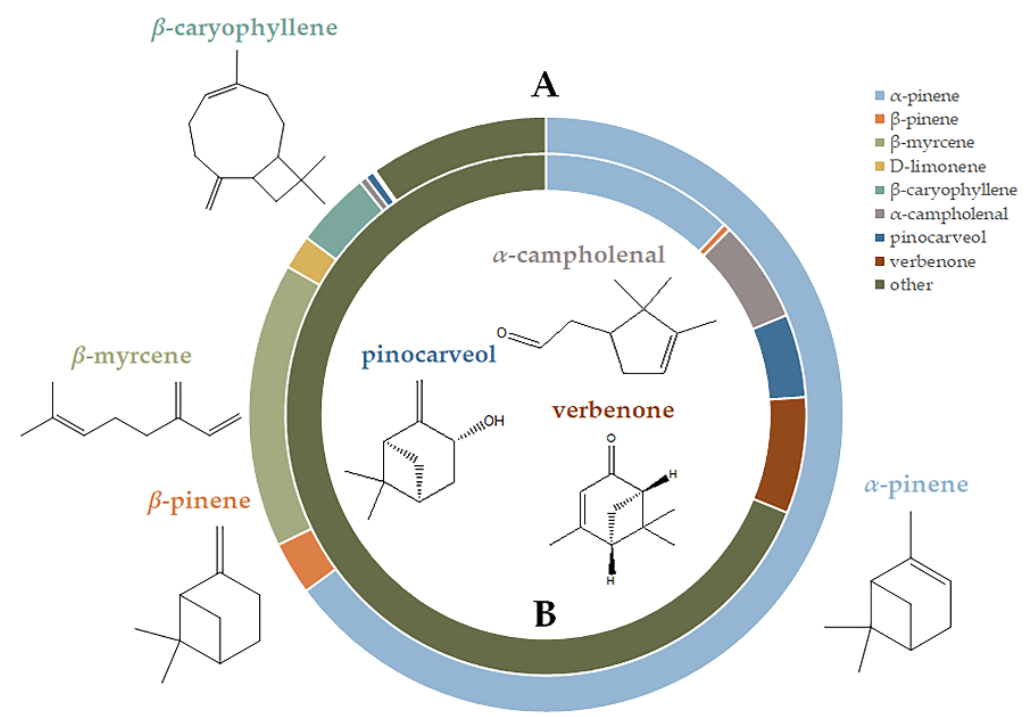

Figure 3. \% Content of different volatiles in CMOs obtained from (A) fresh and (B) 10-year-old resin.

Pinocarvone, however, has been mentioned thus far only in one study of samples from a fresh collection [11]. Moreover, camphene (Rt $11.0 \mathrm{~min}$ ), eluting close to $\alpha$-pinene, appears only in the aged sample, implying a possible isomerization of the latter [38]. Other transformations taking place include the conversion of D-limonene (Rt $14.7 \mathrm{~min}$ ) 
to benzenoid cymene derivatives (Rt $14.6 \mathrm{~min}$ ) and that of perillene and $\alpha$-linalool (Rt $18.2 \mathrm{~min}$ ) to the oxygenated campholene ones (Rt $17.8 \mathrm{~min}$ ). Benzenoid cymene derivatives have also been found to increase in samples of aged wine [65], and as for D-limonene, Karlberg et al. suggested its possible transformation into carvone under air exposure [66].

Similar observations could be made for benzenoid compounds and cymene derivatives such as $p$-cymen-8-ol, carvone (Rt $25.3 \mathrm{~min}$ ), as well as $o-, p$ - and $m$-cymene, which constitute characteristic examples. The presence of $p$-cymene has been reported in three studies of fresh collections $(<0.4 \%)[11,30,60]$. Moreover, in the aged collection sample, myrtenal (Rt $23.1 \mathrm{~min}$ ) seemed to co-elute with $p$-cymen-8-ol (Rt $22.9 \mathrm{~min}$ ), a compound referenced only in one study of a fresh collection of mastic [11]. o-Methyl-anisole is a compound found both in fresh and aged oils; however, in the 10-year old oil, it seemed to co-elute with 1-ethenyl-2,4-dimethylbenzene or 1-methyl-4-(2-propenyl)-benzene (Rt $14.0 \mathrm{~min}$ ). In accordance with our findings, in the only work studying the ageing of CMG during a 3-year storage period, camphene, limonene, $\beta$-pinene, $p$-cymene, myrtenal, and trans-carveol were augmented [38]. An interesting and somewhat contradictory observation, though, was that $\beta$-pinene and $D$-limonene seem to be increased in the 2-year storage verifying the previous reference whilst the first decreases significantly $(<1 \%)$ and the second disappears in the 10-year-old sample.

Finally, regarding the presence of dimyrcenes, their content was found higher in the 2-year collection sample compared to the fresh ones, but they were absent from the 10-year collection. A plausible explanation could be the gradual polymerization of myrcene first to its dimer (after a short storage period) and then to its polymer over a longer ageing time. Dimyrcenes have only been detected in fresh collections in the Seville's and Izmir's essential oils of Pistacia lentiscus resin at levels similar to those presented herein $[11,60]$. Finally, two ketones, namely 4-acetyl-1-methylcycloxene (Rt $13.3 \mathrm{~min}$ ) and 2-undecanone (Rt $27.2 \mathrm{~min}$ ), have been detected only in the 10-year-old sample. The existence of 2 undecanone at a low rate $(<0.2 \%)$ has been reported in only two studies analyzing samples of fresh collections [30,60].

To summarize, according to our findings, the oil produced from the resin aged for 2 years presented few differences with the fresh ones, with the only evident exception being $\beta$-myrcene, the compound, which seems to be the most affected by ageing. On the other hand, in the oil produced from the resin stored for a period longer than 10 years, the chemical composition was completely altered with oxidized products such as verbenone, pinocarveol, and $\alpha$-campholenal dominating the oil's profile. $\alpha$-Pinene is still one of the major constituents of the aged oil, and $\beta$-myrcene is completely absent, probably due to extensive polymerization phenomena.

\subsection{Antifungal and Antibacterial Effects of Resins and Essential Oils}

All resins (CMG_1-7) and essential oils (CMO_1-7) from fresh collections together with the resin stored for 2 years (CMG_8) and the respective oil (CMO_8) were tested for their antifungal and antibacterial activity. In vivo growth tests were performed against the following microorganisms: Fungi: Aspergillus nidulans, Aspergillus fumigatus, Candida albicans, Mucor circinelloides, and Rhizopus oryzae. Bacteria: Escherichia coli, Pseudomonas aeruginosa, and Bacillus subtilis. The rationale for the choice of fungi to be tested is the following. A. nidulans is a non-pathogenic well-studied model system that permits unique genetic, molecular, and cellular approaches [67] that would have enabled us to address the mechanism of any potential action of the mastic compounds tested. A. fumigatus and C. albicans are two of the most prominent major fungal (ascomycete) human pathogens in immunocompromised people $[68,69]$. M. circinelloides and $R$. oryzae are clinical isolates of Mucorales, a genus of emerging pathogens that often includes strains resistant to antifungal pharmacological therapy [70-72]; provided by Dr. George Chamillos, IMMB]. The bacteria tested are standard strains that represent Gram- (E. coli) or Gram+ (B. subtilis) model eubacteria, whereas P. aeruginosa is a common Gram- bacterium that can cause disease in plants and animals, including humans. 
Figure 4 and Figure S6 summarize results obtained with fungi and bacteria, respectively.
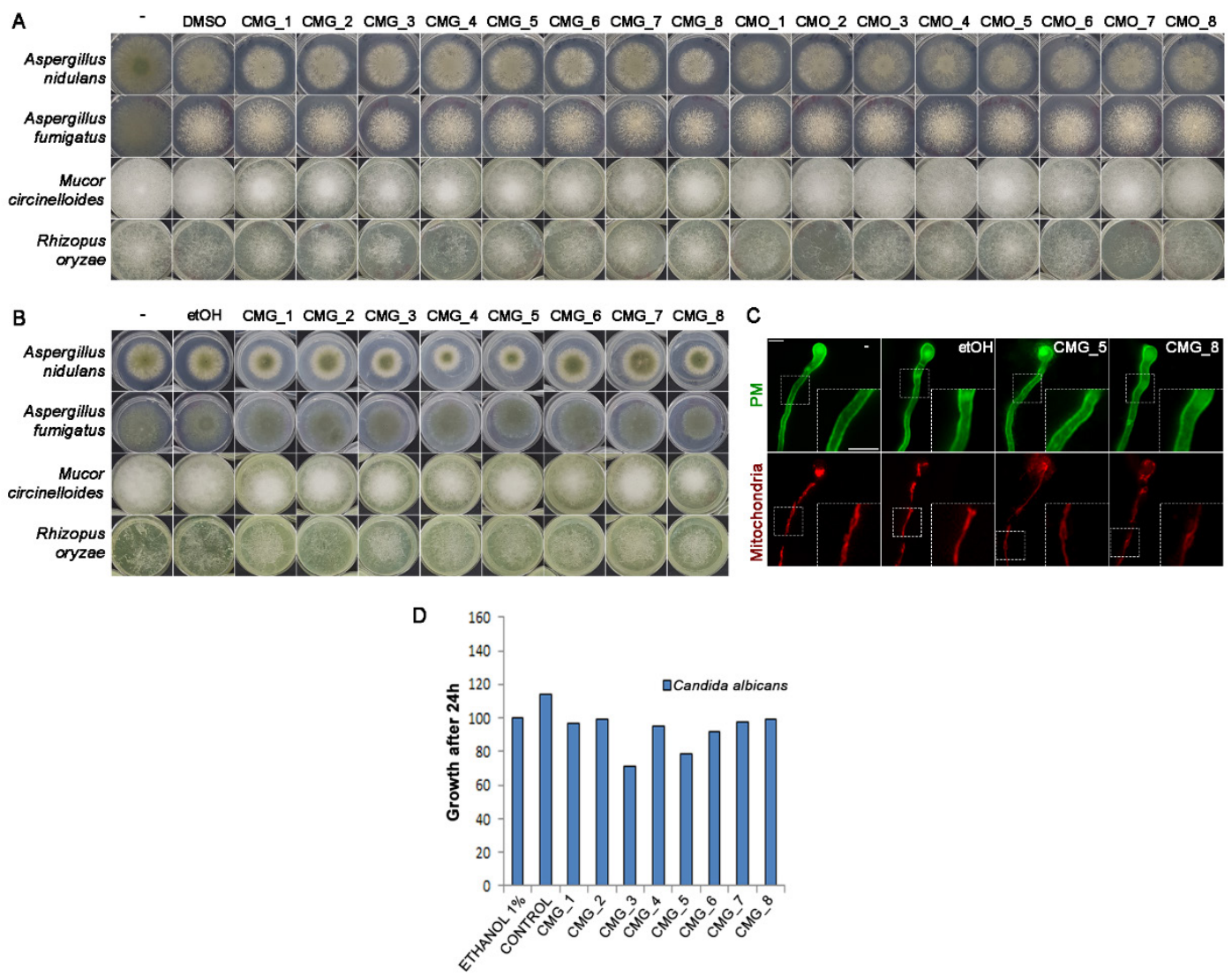

Figure 4. Effect of resins and essential oils against fungi. (A,B) Comparative growth test of A. nidulans, A. fumigatus, M. circinelloides, and R. oryzae on Minimal Media (MM) after 3 days at $37^{\circ} \mathrm{C}$ in the presence or absence (control/solvent) of samples. In (A) Mastic resins (CMG_1-8) and essential oils (CMO_1-8) were diluted in DMSO and added to MM in a final concentration of $0.2 \mathrm{mg} / \mathrm{mL}(1 \%$ DMSO). In (B), mastic resins were diluted in ethanol and added to the minimal media in a final concentration of $0.4 \mathrm{mg} / \mathrm{mL}$ (1\% ethanol). (C) Epifluorescence microscopy of an A. nidulans strain co-expressing a plasma membrane (PM) purine transporter tagged with GFP (AzgA-GFP) and a mitochondrial marker tagged with DsRed (CitA-DsRed) in the presence or absence of resins (CMG_1-8). CMG_5 and CMG_8 depict representative results of the effect of all mastic resins tested. Scale bar: $5 \mu \mathrm{m}$ (D) The bar graph depicts growth rate of Candida albicans in the presence of mastic resins (CMG_1-8) after $24 \mathrm{~h}$ of incubation. The standard deviation in all cases was $<1 \%$.

Figure $4 \mathrm{~A}$ shows that all samples tested, when dissolved in DMSO, had minor or no effect on fungal growth. More specifically, in the case of $A$. nidulans, all led to a moderate reduction in colony diameter and no effect on apparent conidiospore production. Among those, CMG_8 $(2.2 \mathrm{~cm})$, followed by CMG_6 and CMG_1 $(2.5 \mathrm{~cm})$, had the most prominent effect, compared to the control $(3.2 \mathrm{~cm})$. It is important to note that the most potent was the most aged between the analyzed samples. The respective oils (CMO_1-8) had practically no effect on $A$. nidulans colonies. CMG_8 also had the strongest effect on A. fumigatus ( $2.5 \mathrm{~cm}$ versus $3.2 \mathrm{~cm}$ in control), while other CMGs had minor effects on growth. Nearly all CMGs had an effect on hyphal density in M. circinelloides, not evident in R. oryzae, but did not affect the rate of colony growth in any of the two Mucorales. CMOs had no effect on $M$. circinelloides, but CMO_2 and CMO_7 led to a significant reduction of hyphal density in R. oryzae.

Based on these results, we retested all CMGs at 2-fold increased concentration, this time diluted in ethanol. Results shown in Figure 4B demonstrate that CMG_4,CMG_5, and CMG_8 had a negative effect on A. nidulans colony diameter, reducing it from $2.2 \mathrm{~cm}$ to 1.4-1.7 cm, while again CMG_8 also led to a significant reduction of growth in A. fumigatus 
(1.9 cm compared to $2.6 \mathrm{~cm}$ in the control). Overall, CMG_8 showed the most consistent negative effect on the growth of both Aspergilli (22-37\% reduction of colony diameter).

As far as it concerns Mucorales, again, most CMGs led to a significant reduction in hyphal density in M. circinelloides, but not in R. oryzae. Based on the result for growth tests, it became apparent that the CMG_8 had a promising antifungal effect mostly against Aspergilli, but possibly also against $M$. circinelloides. To investigate possible cellular defects underlying its action, but also of other CMG and CMO samples, we took advantage of available genetic strains expressing specific fluorescent molecular markers in A. nidulans, and in particular a strain stably expressing a plasma membrane (PM) protein (purine transporter AzgA) and a mitochondrial protein (citrate synthase CitA), tagged with GFP or DsRed, respectively $[73,74]$. Several known antifungal agents have a targeting effect on the cell wall or PM biosynthesis or in mitochondrial functioning and morphology [72,75]. In previous reports, oils have been shown to have minimal and variable activity against some fungi (e.g., Saccharomyces cerevisiae, Zygosaccharomyces bailii, Aspergillus flavus, Penicillium roquefortii, Eurotium amstelodami; [76]), but to our knowledge, there were practically no reports on mastic resins against fungi, except a report related to the phytopathogenic fungus Rhizoctonia solani [61]. Figure 4C shows representative results with CMG_8 and CMG_5. None of the samples tested had any detectable effect on the general morphology of A. nidulans hyphal cells, or in the localization, stability, and turnover of PM or mitochondrial proteins.

As shown in Figure 4D, we did not detect any significant effect against $C$. albicans. Moreover, all tested samples did not seem to have any significant effect on the growth of the bacterial strains tested. Figure S6 shows optical densities of bacterial strains after $24 \mathrm{~h}$ of growth in the presence of samples compared to the control culture. No effect was also observed at earlier incubation times ( 8 and $16 \mathrm{~h}$, data not shown).

From the aforementioned results, specific CMGs do have a moderate antifungal activity, which apparently is not directly related to the integrity of the cell wall, the PM of the functioning of mitochondria. It is interesting to note that the most potent resin was the one after 2 years' storage, while the respective oil did not present any activity. A reasonable assumption is that degradation and/or oxidized forms of terpenes were most probably responsible for the observed effects, while a possible role of the relatively increased levels of poly- $\beta$-myrcene cannot also be ignored.

\section{Conclusions}

In the present study, 11 different authentic mastic resins (CMG) from different collection times were investigated together with their respective essential oils (CMO). All samples were analyzed by HPTLC using the elution system proposed by the Ph.Eur. monograph and a new one developed in-house with the new system providing an improved separation and a higher resolution for the detected constituents. HPTLC could be used as a fast screening method for $\mathrm{CMG}$ and $\mathrm{CMO}$ samples and is even suitable for the detection of the ageing effect on both sample types. Based on our results, the two criteria set by the Pharmacopoeia, namely distillation yield, and the TLC method, were found to be insufficient and inaccurate for the successful identification of the resin and adulteration detection and, therefore, they should be reconsidered.

CMOs were also analyzed by GC-MS, and more than 30 compounds were identified in the fresh oils, and specific content ranges were proposed for the major components of CMOs originating exclusively from P. lentiscus var Chia. Major differences were observed in CMO's major compound classes during the ageing process. Monoterpene hydrocarbons were found to gradually decrease over time, followed by a simultaneous increase in oxygenated monoterpenes and benzenoids. A similar pattern is observed between sesquiterpene hydrocarbons and oxygenated sesquiterpenes. $\alpha$-Pinene and $\beta$-myrcene, which are quality markers for $\mathrm{CMO}$, were found in high levels in fresh samples, also showing a continuing decline over time. However, $\beta$-myrcene seems to be a more suitable marker of ageing since, due to extensive polymerization after 10 years, it is not detectable. Similarly, camphene 
appears only in aged samples as an isomerization product of $\alpha$-pinene. Amongst these lines, other compounds such as $\alpha$-campholenal, pinocarveol, verbenone, and pinocarvone could also be proposed as ageing markers.

Regarding the antimicrobial properties of the samples, overall, the resins were found to be more potent compared to oils and specifically against $A$. nidulans, A. fumigatus, and $M$. circinelloides as judged on their effect on colony diameter and growth in general. Here, we also obtained direct cellular evidence that the moderate effect of the most potent mastic compounds does not seem to be associated with major morphological defects of the PM, nuclei organization, or the mitochondria of $A$. nidulans. Interestingly also, the most active was compound CMG_8 was a resin sample stored for 2 years, while the relative fresh sample showed moderate activity.

Supplementary Materials: The following are available online at https:/ /www.mdpi.com/2227-971 7/9/3/418/s1, Figure S1: HPTLC chromatogram of CMG with the Ph. Eur. Method. Detection at (A) $254 \mathrm{~nm}$ and (B) $366 \mathrm{~nm}$. Figure S2: HPTLC chromatogram of CMO with the Ph. Eur. Method. Detection at (A) $254 \mathrm{~nm}$ and (B) $366 \mathrm{~nm}$. Figure S3: HPTLC chromatogram of CMG developed with the in-house method. Detection at A) $254 \mathrm{~nm}$ and B) $366 \mathrm{~nm}$. Figure S4: HPTLC chromatogram of CMO developed with the in-house method. Detection at (A) $254 \mathrm{~nm}$ and (B) $366 \mathrm{~nm}$. Figure S5: Zoomed superimposed total ion chromatograms (TIC) of a fresh (CMO_1) and an aged sample (CMO_9). Figure S6: Effect of resins and essential oils against bacteria. Comparison of bacterial growth (E. coli, P. aeruginosa and B. subtilis), as expressed by measuring optical density values $(550 \mathrm{~nm})$, in the presence of resins (CMG_1-8) or essential oils (CMO_1-8), after $24 \mathrm{~h}$ of incubation at $37^{\circ} \mathrm{C}$. Values in graphs represent $\%$ of growth in the presence of mastic extracts relative to control (no mastic extract added) taken as 100\%. In the left panel mastic resins and essential oils diluted in DMSO were added at a final concentration of $0.2 \mathrm{mg} / \mathrm{mL}(1 \%$ DMSO), whilst in the right penal mastic resins diluted in ethanol were added at final concentration of $0.4 \mathrm{mg} / \mathrm{mL}$ ( $1 \%$ ethanol). Standard deviation in all cases was $<1 \%$. Table S1: Minimum, maximum, and average values for the ratios of major compounds in CMO samples (CMO_1-8, CMO_9).

Author Contributions: Conceptualization, V.K.P., G.D., and M.H.; methodology, V.K.P., E.V.M., S.D., M.D., and A.A.; resources, G.D. and M.H.; writing—original draft preparation, V.K.P., S.D., M.D., and E.V.M.; writing - review and editing, A.A., G.D., and M.H.; visualization, V.K.P., S.D., M.D., and E.V.M.; supervision, G.D. and M.H.; project administration, V.K.P. and M.H.; funding acquisition, G.D. and M.H. All authors have read and agreed to the published version of the manuscript.

Funding: Vasiliki K. Pachi is co-financed by Greece and the European Union (European Social FundESF) through the Operational Programme «Human Resources Development, Education and Lifelong Learning" in the context of the project "Strengthening Human Resources Research Potential via Doctorate Research" (MIS-5000432), implemented by the State Scholarships Foundation (IK $\Upsilon$ ). Eleni V. Mikropoulou is financed through a Stavros Niarchos Foundation (SNF) grant to the National and Kapodistrian University of Athens. The present work was co-funded by the European Union (ERDF) and Greek national funds through the Operational Program "Competitiveness, Entrepreneurship and Innovation", under the call "STRENGTHENING RESEARCH AND INNOVATION INFRASTRUCTURES" (project code: 5002803-PlantUP).

Institutional Review Board Statement: Not applicable.

Informed Consent Statement: Not applicable.

Data Availability Statement: The data presented in this study are available on request from the corresponding author.

Acknowledgments: The authors would like to thank Chios Mastiha Growers Association and especially Smyrnioudis Ilias for kindly providing the CMG samples. The authors are also thankful to Iasis Pharma Hellas S.A. for the valuable information and assistance.

Conflicts of Interest: The authors declare no conflict of interest. 


\section{References}

1. Pachi, V.K.; Mikropoulou, E.V.; Gkiouvetidis, P.; Siafakas, K.; Argyropoulou, A.; Angelis, A.; Mitakou, S.; Halabalaki, M. Traditional Uses, Phytochemistry and Pharmacology of Chios Mastic Gum (Pistacia lentiscus Var. Chia, Anacardiaceae): A Review. J. Ethnopharmacol. 2020, 254. [CrossRef]

2. European Commission. Commission Regulation (EC) No $123 / 97$ of 23 January 1997 Supplementing the Annex to Commission Regulation (EC) No 1107/96 on the Registration of Geographical Indications and Designations of Origin. Off. J. 1997, L 22, 19-20.

3. United Nations Educational, Scientific and Cultural Organization. Decision of the Intergovernmental Committee: 9.COM 10.18, Inscribing the Know-How of Cultivating Mastic on the Island of Chios on the Representative List of the Intangible Cultural Heritage of Humanity. 2014. Available online: https://ich.unesco.org/en/Decisions/9.COM/10.18 (accessed on 1 November 2020).

4. European Medicines Agency. Assessment Report on Pistacia lentiscus, L., Resin (Mastix). 2015. Available online: https://www. ema.europa.eu/en/documents/herbal-report/draft-assessment-report-pistacia-lentiscus-1-resin-mastic_en.pdf (accessed on 1 November 2020).

5. Dioscorides, P. De Materia Medica, 1st ed.; Militos: Alimos, Greece, 1999.

6. Galen. Pharmacy, 2nd ed.; Lindsay and Blakiston: Philadelphia, PA, UAS, 1846.

7. Moussaieff, A.; Fride, E.; Amar, Z.; Lev, E.; Steinberg, D.; Gallily, R.; Mechoulam, R. The Jerusalem Balsam: From the Franciscan Monastery in the Old City of Jerusalem to Martindale 33. J. Ethnopharmacol. 2005, 101, 16-26. [CrossRef] [PubMed]

8. Assimopoulou, A.N.; Zlatanos, S.N.; Papageorgiou, V.P. Antioxidant Activity of Natural Resins and Bioactive Triterpenes in Oil Substrates. Food Chem. 2005, 92, 721-727. [CrossRef]

9. Dedoussis, G.V.Z.; Kaliora, A.C.; Psarras, S.; Chiou, A.; Mylona, A.; Papadopoulos, N.G.; Andrikopoulos, N.K. Antiatherogenic Effect of Pistacia lentiscus via GSH Restoration and Downregulation of CD36 MRNA Expression. Atherosclerosis 2004, 174, $293-303$. [CrossRef] [PubMed]

10. Kaliora, A.C.; Stathopoulou, M.G.; Triantafillidis, J.K.; Dedoussis, G.V.Z.; Andrikopoulos, N.K. Chios Mastic Treatment of Patients with Active Crohn's Disease. World J. Gastroenterol. 2007, 13, 748-753. [CrossRef] [PubMed]

11. Tabanca, N.; Nalbantsoy, A.; Kendra, P.E.; Demirci, F.; Demirci, B. Chemical Characterization and Biological Activity of the Mastic Gum Essential Oils of Pistacia lentiscus Var. Chia from Turkey. Molecules 2020, 25, 2136. [CrossRef] [PubMed]

12. Vallianou, I.; Peroulis, N.; Pantazis, P.; Hadzopoulou-Cladaras, M. Camphene, a Plant-Derived Monoterpene, Reduces Plasma Cholesterol and Triglycerides in Hyperlipidemic Rats Independently of HMG-CoA Reductase Activity. PLoS ONE 2011, 6, e20516. [CrossRef] [PubMed]

13. Andreadou, I.; Mitakou, S.; Paraschos, S.; Efentakis, P.; Magiatis, P.; Kaklamanis, L.; Halabalaki, M.; Skaltsounis, L.; Iliodromitis, E.K. "Pistacia lentiscus", L. Reduces the Infarct Size in Normal Fed Anesthetized Rabbits and Possess Antiatheromatic and Hypolipidemic Activity in Cholesterol Fed Rabbits. Phytomedicine 2016, 23, 1220-1226. [CrossRef] [PubMed]

14. Tzani, A.I.; Doulamis, I.P.; Konstantopoulos, P.S.; Pasiou, E.D.; Daskalopoulou, A.; Iliopoulos, D.C.; Georgiadis, I.V.; Kavantzas, N.; Kourkoulis, S.K.; Perrea, D.N. Chios Mastic Gum Decreases Renin Levels and Ameliorates Vascular Remodeling in Renovascular Hypertensive Rats. Biomed. Pharmacother. 2018, 105, 899-906. [CrossRef]

15. Spyridopoulou, K.; Tiptiri-Kourpeti, A.; Lampri, E.; Fitsiou, E.; Vasileiadis, S.; Vamvakias, M.; Bardouki, H.; Goussia, A.; Malamou-Mitsi, V.; Panayiotidis, M.I.; et al. Dietary Mastic Oil Extracted from Pistacia lentiscus Var. Chia Suppresses Tumor Growth in Experimental Colon Cancer Models. Sci. Rep. 2017, 7, 3782-3796. [CrossRef] [PubMed]

16. Magkouta, S.; Stathopoulos, G.T.; Psallidas, I.; Papapetropoulos, A.; Kolisis, F.N.; Roussos, C.; Loutrari, H. Protective Effects of Mastic Oil from Pistacia lentiscus Variation Chia against Experimental Growth of Lewis Lung Carcinoma. Nutri. Cancer 2009, 61, 640-648. [CrossRef] [PubMed]

17. Loutrari, H.; Magkouta, S.; Pyriochou, A.; Koika, V.; Kolisis, F.N.; Papapetropoulos, A.; Roussos, C. Mastic Oil from Pistacia lentiscus Var. Chia Inhibits Growth and Survival of Human K562 Leukemia Cells and Attenuates Angiogenesis. Nutr. Cancer 2006, 55, 86-93. [CrossRef] [PubMed]

18. Loutrari, H.; Magkouta, S.; Papapetropoulos, A.; Roussos, C. Mastic Oil Inhibits the Metastatic Phenotype of Mouse Lung Adenocarcinoma Cells. Cancers 2011, 3, 789-801. [CrossRef] [PubMed]

19. Buriani, A.; Fortinguerra, S.; Sorrenti, V.; Dall'Acqua, S.; Innocenti, G.; Montopoli, M.; Gabbia, D.; Carrara, M. Human Adenocarcinoma Cell Line Sensitivity to Essential Oil Phytocomplexes from Pistacia Species: A Multivariate Approach. Molecules 2017, 22, 1336. [CrossRef] [PubMed]

20. Papada, E.; Amerikanou, C.; Torović, L.; Kalogeropoulos, N.; Tzavara, C.; Forbes, A.; Kaliora, A.C. Plasma Free Amino Acid Profile in Quiescent Inflammatory Bowel Disease Patients Orally Administered with Mastiha (Pistacia lentiscus); a Randomised Clinical Trial. Phytomedicine 2019, 56, 40-47. [CrossRef] [PubMed]

21. Triantafyllou, A.; Chaviaras, N.; Sergentanis, T.N.; Protopapa, E.; Tsaknis, J. Chios Mastic Gum Modulates Serum Biochemical Parameters in a Human Population. J. Ethnopharmacol. 2007, 111, 43-49. [CrossRef]

22. Kartalis, A.; Didagelos, M.; Georgiadis, I.; Benetos, G.; Smyrnioudis, N.; Marmaras, H.; Voutas, P.; Zotika, C.; Garoufalis, S.; Andrikopoulos, G. Effects of Chios Mastic Gum on Cholesterol and Glucose Levels of Healthy Volunteers: A Prospective, Randomized, Placebo-Controlled, Pilot Study (CHIOS-MASTIHA). Eur. J. Prev. Cardiol. 2015, 23, 722-729. [CrossRef] [PubMed] 
23. Kontogiannis, C.; Georgiopoulos, G.; Loukas, K.; Papanagnou, E.-D.; Pachi, V.K.; Bakogianni, I.; Laina, A.; Kouzoupis, A.; Karatzi, K.; Trougakos, I.P.; et al. Chios Mastic Improves Blood Pressure Haemodynamics in Patients with Arterial Hypertension: Implications for Regulation of Proteostatic Pathways. Eur. J. Prev. Cardiol. 2019, 26, 328-331. [CrossRef]

24. Sterer, N. Antimicrobial Effect of Mastic Gum Methanolic Extract Against Porphyromonas gingivalis. J. Med. Food 2006, 9, $290-292$. [CrossRef]

25. Koychev, S.; Dommisch, H.; Chen, H.; Pischon, N. Antimicrobial Effects of Mastic Extract Against Oral and Periodontal Pathogens. J. Periodontol. 2017, 88, 511-517. [CrossRef]

26. Miyamoto, T.; Okimoto, T.; Kuwano, M. Chemical Composition of the Essential Oil of Mastic Gum and Their Antibacterial Activity Against Drug-Resistant Helicobacter pylori. Nat. Prod. Bioprospecting 2014, 4, 227-231. [CrossRef]

27. Karygianni, L.; Cecere, M.; Skaltsounis, A.L.; Argyropoulou, A.; Hellwig, E.; Aligiannis, N.; Wittmer, A.; Al-Ahmad, A. HighLevel Antimicrobial Efficacy of Representative Mediterranean Natural Plant Extracts against Oral Microorganisms. BioMed Res. Int. 2014, 2014, 839019. [CrossRef] [PubMed]

28. Tassou, C.C.; Nychas, G.J.E. Antimicrobial Activity of the Essential Oil of Mastic Gum (Pistacia lentiscus Var. Chia) on Gram Positive and Gram Negative Bacteria in Broth and in Model Food System. Int. Biodeterior. Biodegrad. 1995, 36, 411-420. [CrossRef]

29. Vrouvaki, I.; Koutra, E.; Kornaros, M.; Avgoustakis, K.; Lamari, F.N.; Hatziantoniou, S. Polymeric Nanoparticles of Pistacia lentiscus Var. Chia Essential Oil for Cutaneous Applications. Pharmaceutics 2020, 12, 353. [CrossRef] [PubMed]

30. Magiatis, P.; Melliou, E.; Skaltsounis, A.L.; Chinou, I.B.; Mitaku, S. Chemical Composition and Antimicrobial Activity of the Essential Oils of Pistacia lentiscus Var. Chia. Planta Med. 1999, 65, 749-752. [CrossRef]

31. Sharifi, M.S.; Hazell, S.L. Fractionation of Mastic Gum in Relation to Antimicrobial Activity. Pharmaceuticals 2009, 2, 2-10. [CrossRef]

32. Paraskevopoulou, A.; Kiosseoglou, V. Chios Mastic Gum and Its Food Applications. In Functional Properties of Traditional Foods; Springer: Berlin/Heidelberg, Germany, 2016; pp. 271-287.

33. Fazeli-Nasab, B.; Fooladvand, Z. Classification and Evaluation of Medicinal Plant and Medicinal Properties of Mastic. Int. J. Adv. Biol. Biomed. Res. 2014, 2, 2155-2161.

34. CMGA. Available online: https://www.gummastic.gr/en (accessed on 5 November 2020).

35. Mavrakis, C.; Kiosseoglou, V. The Structural Characteristics and Mechanical Properties of Biopolymer/Mastic Gum Microsized Particles Composites. Food Hydrocoll. 2008, 22, 854-861. [CrossRef]

36. Paraschos, S. Phytochemical and Pharmacological Study of Chios Mastic Gum; National and Kapodistrian University of Athens: Athens, Greece, 2010. [CrossRef]

37. Xynos, N.; Termentzi, A.; Fokialakis, N.; Skaltsounis, L.A.; Aligiannis, N. Supercritical $\mathrm{CO}_{2}$ extraction of Mastic Gum and Chemical Characterization of Bioactive Fractions Using LC-HRMS/MS and GC-MS. J. Supercrit. Fluids 2018, 133, 349-356. [CrossRef]

38. Papanicolaou, D.; Melanitou, M.; Katsaboxakis, K. Changes in Chemical Composition of the Essential Oil of Chios "Mastic Resin" from Pistacia lentiscus Var. Chia Tree during Solidification and Storage. Dev. Food Sci. 1995, 37, 303-310. [CrossRef]

39. Daferera, D.; Pappas, C.; Tarantilis, P.A.; Polissiou, M. Quantitative Analysis of $\alpha$-Pinene and $\beta$-Myrcene in Mastic Gum Oil Using FT-Raman Spectroscopy. Food Chem. 2002, 77, 511-515. [CrossRef]

40. Koutsoudaki, C.; Krsek, M.; Rodger, A. Chemical Composition and Antibacterial Activity of the Essential Oil and the Gum of Pistacia lentiscus Var. Chia. J. Agric. Food Chem. 2005, 53, 7681-7685. [CrossRef]

41. Hellenic Republic, Ministry of Rural Development and Food. Available online: www.minagric.gr (accessed on 25 November 2020).

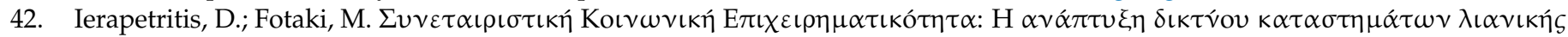

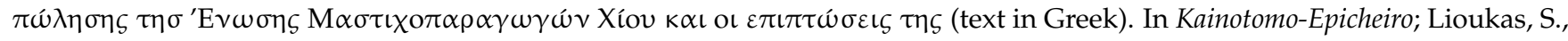
Ed.; Athens University of Economics and Business: Athens, Greece, 2013.

43. Rigling, M.; Fraatz, M.A.; Trögel, S.; Sun, J.; Zorn, H.; Zhang, Y. Aroma Investigation of Chios Mastic Gum (Pistacia lentiscus Variety Chia) Using Headspace Gas Chromatography Combined with Olfactory Detection and Chiral Analysis. J. Agric. Food Chem. 2019, 67, 13420-13429. [CrossRef]

44. European Pharmacopoeia 9.0; 2011; Volume 1, pp. 2277-2278. Available online: https://www.tsoshop.co.uk/?DI=647707 (accessed on 28 January 2021).

45. Adams, R.P. Identification of Essential Oil Components by Gas Chromatography/Mass Spectrometry, 4th ed.; Allured Publishing Corporation: Carol Stream, IL, USA, 2007.

46. NIST. Available online: https://webbook.nist.gov/chemistry/ (accessed on 20 October 2020).

47. Maryutina, T.A.; Savonina, E.Y.; Fedotov, P.S.; Smith, R.M.; Siren, H.; Hibbert, D.B. Terminology of Separation Methods (IUPAC Recommendations 2017). Pure Appl. Chem. 2018, 90, 181-213. [CrossRef]

48. FGSC. Available online: http:/ / www.fgsc.net. (accessed on 2 November 2020).

49. Papanicolaou, D.; Melanitou, M.; Katsaboxakis, K. Effect of $\alpha$-Tocopherol (Vitamin E) on the Retention of Essential Oil, Color and Texture of Chios Mastic Resin during Storage. Dev. Food Sci. 1998, 40, 689-694. [CrossRef]

50. Papageorgiou, V.P.; Mellidis, A.S.; Argyriadou, N. The Chemical Composition of the Essential Oil of Mastic Gum. J. Essent. Oil Res. 1991, 3, 107-110. [CrossRef] 
51. Paraschos, S.; Magiatis, P.; Gikas, E.; Smyrnioudis, I.; Skaltsounis, A.-L. Quality Profile Determination of Chios Mastic Gum Essential Oil and Detection of Adulteration in Mastic Oil Products with the Application of Chiral and Non-Chiral GC-MS Analysis. Fitoterapia 2016, 114, 12-17. [CrossRef] [PubMed]

52. Van Den Berg, K.J.; Van Der Horst, J.; Boon, J.J.; Sudmeijer, O.O. Cis-1,4-Poly- $\beta$-Myrcene: The Structure of the Polymeric Fraction of Mastic Resin (Pistacia lentiscus, L.) Elucidated. Tetrahedron Lett. 1998, 39, 2645-2648. [CrossRef]

53. Behr, A.; Johnen, L. Myrcene as a Natural Base Chemical in Sustainable Chemistry: A Critical Review. ChemSusChem 2009, 2, 1072-1095. [CrossRef] [PubMed]

54. Mikropoulou, E.V.; Petrakis, E.A.; Argyropoulou, A.; Halabalaki, M.; Skaltsounis, L.A. Quantification of Bioactive Lignans in Sesame Seeds Using HPTLC Densitometry: Comparative Evaluation by HPLC-PDA. Food Chem. 2019, 288, 1-7. [CrossRef] [PubMed]

55. Meier, B.; Spriano, D. Modern HPTLC-A Perfect Tool for Quality Control of Herbals and Their Preparations. J. AOAC Int. 2010, 93, 1399-1409. [CrossRef] [PubMed]

56. Assimopoulou, A.N.; Papageorgiou, V.P. GC-MS Analysis of Penta- and Tetra-Cyclic Triterpenes from Resins of Pistacia Species. Part, I. Pistacia lentiscus Var. Chia. Biomed. Chromatogr. 2005, 19, 285-311. [CrossRef]

57. Papageorgiou, V.P.; Bakola-Christianopoulou, M.N.; Apazidou, K.K.; Psarros, E.E. Gas Chromatographic-Mass Spectroscopic Analysis of the Acidic Triterpenic Fraction of Mastic Gum. J. Chromatography A 1997, 769, 263-273. [CrossRef]

58. Serifi, I.; Tzima, E.; Bardouki, H.; Lampri, E.; Papamarcaki, T. Effects of the Essential Oil from Pistacia lentiscus Var. Chia on the Lateral Line System and the Gene Expression Profile of Zebrafish (Danio rerio). Molecules 2019, 24, 3919. [CrossRef]

59. Papageorgiou, V.P.; Sagredos, A.N.; Mose, R. GLC-MS Computer Analysis of the Essential Oil of Mastic Gum. Chim. Chronica New Ser. 1981, 10, 119-124.

60. Boelens, M.H.; Jimenez, R. Chemical Composition of the Essential Oils from the Gum and from Various Parts of Pistacia lentiscus L. (Mastic Gum Tree). Flavour Fragr. J. 1991, 6, 271-275. [CrossRef]

61. Duru, M.E.; Cakir, A.; Kordali, S.; Zengin, H.; Harmandar, M.; Izumi, S.; Hirata, T. Chemical Composition and Antifungal Properties of Essential Oils of Three Pistacia Species. Fitoterapia 2003, 74, 170-176. [CrossRef]

62. Burham, B.O.; EL-Kamali, H.H.; EL-Egami, A.A. Volatile Components of the Resin of Pistacia lentiscus "Mistica" Used in Sudanese Traditional Medicine. J. Chem. Pharm. Res. 2011, 3, 478-482.

63. Neuenschwander, U.; Guignard, F.; Hermans, I. Mechanism of the Aerobic Oxidation of $\alpha$-Pinene. ChemSusChem 2010, 3, 75-84. [CrossRef]

64. Neuenschwander, U.; Meier, E.; Hermans, I. Peculiarities of $\beta$-Pinene Autoxidation. ChemSusChem 2011, 4, 1613-1621. [CrossRef] [PubMed]

65. Slaghenaufi, D.; Ugliano, M. Norisoprenoids, Sesquiterpenes and Terpenoids Content of Valpolicella Wines during Aging: Investigating Aroma Potential in Relationship to Evolution of Tobacco and Balsamic Aroma in Aged Wine. Front. Chem. 2018, 6, 1-13. [CrossRef] [PubMed]

66. Karlberg, A.; Magnusson, K.; Nilsson, U. Air Oxidation of D-limonene (the Citrus Solvent) Creates Potent Allergens. Contact Dermat. 1992, 26, 332-340. [CrossRef] [PubMed]

67. Scazzocchio, C. Aspergillus: A Multifaceted Genus. In Encyclopedia of Microbiology; Academic Press: Cambridge, MA, USA, 2009; ISBN 9780123739445.

68. Jerez Puebla, L.E. Fungal Infections in Immunosuppressed Patients. In Immunodeficiency; InTech: Rijeka, Croatia, 2012.

69. Latgé, J.P.; Chamilos, G. Aspergillus Fumigatus and Aspergillosis in 2019. Clin. Microbiol. Rev. 2020, 33. [CrossRef]

70. Ghuman, H.; Voelz, K. Innate and Adaptive Immunity to Mucorales. J. Fungi 2017, 3, 48. [CrossRef]

71. Chamilos, G.; Lewis, R.E.; Kontoyiannis, D.P. Lovastatin Has Significant Activity against Zygomycetes and Interacts Synergistically with Voriconazole. Antimicrob. Agents Chemother. 2006, 50, 96-103. [CrossRef]

72. Wiederhold, N.P. Antifungal Resistance: Current Trends and Future Strategies to Combat. Infect. Drug Resist. 2017, 10, 249-259. [CrossRef] [PubMed]

73. Pantazopoulou, A.; Lemuh, N.D.; Hatzinikolaou, D.G.; Drevet, C.; Cecchetto, G.; Scazzocchio, C.; Diallinas, G. Differential Physiological and Developmental Expression of the UapA and AzgA Purine Transporters in Aspergillus nidulans. Fungal Genet. Biol. 2007, 44, 627-640. [CrossRef] [PubMed]

74. Toews, M.W.; Warmbold, J.; Konzack, S.; Rischitor, P.; Veith, D.; Vienken, K.; Vinuesa, C.; Wei, H.; Fischer, R. Establishment of MRPF1 as a Fluorescent Marker in Aspergillus nidulans and Construction of Expression Vectors for High-Throughput Protein Tagging Using Recombination in Vitro (GATEWAY). Curr. Genet. 2004, 45, 383-389. [CrossRef] [PubMed]

75. Sant, D.G.; Tupe, S.G.; Ramana, C.V.; Deshpande, M.V. Fungal Cell Membrane—Promising Drug Target for Antifungal Therapy. J. Appl. Microbiol. 2016, 121, 1498-1510. [CrossRef] [PubMed]

76. Gkogka, E.; Hazeleger, W.C.; Posthumus, M.A.; Beumer, R.R. The Antimicrobial Activity of the Essential Oil of Pistacia lentiscus Var. Chia. J. Essent. Oil Bear. Plants 2013, 16, 714-729. [CrossRef] 